\title{
Dynamic Forces of Swaying Human and Responses of Temporary Demountable Grandstand Based on Experiment and Simulation
}

\author{
Lin He, ${ }^{1,2}$ Jian Yuan $\mathbb{D}^{1,2,3}$ Feng Fan, ${ }^{1,2}$ and Cong Liu ${ }^{1,2}$ \\ ${ }^{1}$ Key Lab of Structures Dynamic Behavior and Control of Ministry of Education, Harbin Institute of Technology, Harbin 150090, \\ China \\ ${ }^{2}$ School of Civil Engineering, Harbin Institute of Technology, Harbin 150090, China \\ ${ }^{3}$ Rocket Force University of Engineering, Xi'an 710025, China \\ Correspondence should be addressed to Jian Yuan; yuanjian_850809@126.com
}

Received 19 June 2018; Revised 3 September 2018; Accepted 19 September 2018; Published 7 November 2018

Academic Editor: Gilbert R. Gillich

Copyright (c) 2018 Lin He et al. This is an open access article distributed under the Creative Commons Attribution License, which permits unrestricted use, distribution, and reproduction in any medium, provided the original work is properly cited.

\begin{abstract}
Modern temporary demountable structures must be designed to withstand the dynamic forces which generated by crowd occupants. The human forces and that cause the dynamic responses of structure have become an important research topic. In this paper, the human swaying forces and responses of temporary demountable grandstand are studied through an experimental program. The dynamic forces that were induced by participants who have swayed $0.5-1.8 \mathrm{~Hz}$ are recorded by a triaxial human biomechanics force plate, and the structural dynamic responses of a temporary grandstand occupied twenty swaying human are investigated. The constraint parameters of swaying force model which derives from a semiempirical formula are developed and can be represented for crowd. Crowd can able to induce excessive lateral vibration of structure due to the lower frequency of temporary grandstand and make them in panic. The dynamic responses of a large temporary grandstand are predicted by finite element method, and the results show that a person was considered as a load with stiffness and damping, and the structural lateral dynamic responses are higher than the model of person just only considered as load.
\end{abstract}

\section{Introduction}

Lateral vibration of temporary demountable grandstands (TDGs) seems to be particularly vulnerable to loads which derived from crowds had swaying movements because its lightweight structural components can be rapidly assembled, easily dismantled, and reused, which results in low stiffness of structure at lateral direction, and the natural frequencies of it are close to swaying frequencies. Therefore, structural vibrations triggered by crowds have often been observed during sporting events $[1,2]$ or rock concerts [3], and even caused spectator discomfort or panic, regrettably leading to several disasters [4-6], especially 1600 persons were injured and 18 persons died due to crowd activities which led to structure collapse [5]. Also Brito and Pimentel [6] analyzed the collapse of ninety-three temporary grandstands and found that most of them were damaged by crowd movements at sport or performance activities. In order to avoid excessive vibrations or collapses for assemble structures, it is necessary to investigate human swaying forces and to understand the interactions between human and structure.

Although Tilden is the first person to measure human swaying force in 1913, he studied on the dynamic forces of 22 subjects swaying at $1.1 \mathrm{~Hz}$, which was cited in Saul and Tuan [7]. Over two decades ago, Reid et al. [8] highlighted the absence of experimental data for horizontal crowd loads, and Ellis et al. [9] estimated horizontal crowd loads to be about 7-10 percent of vertical crowd loads in 2000, Yao et al. [10] designed an experiment that a stationary person subject swaying side to side on a flexible test rig to analysis the human forces. There are a few studies about temporary grandstand with considering human swaying forces, Gibbs [13] tested six persons swayed at a temporary grandstand and investigated structural dynamic responses in 1990, and David and Gilbert [14] monitored and analyzed a temporary grandstand at sports activity in 1999. Some studies have analyzed the dynamic performance of temporary grandstand by finite element 
models [15-21] and highlighted the importance of structural lateral dynamic response.

Bearing all this in mind, the model of swaying forces needs to be developed and the swaying crowd-temporary grandstand interactions should be comprehended. The aim of this study was to obtain constrain parameters of swaying force model that derived from a semiempirical formula based on the measured data. In addition, a temporary grandstand occupied twenty participants who swayed between $0.5 \mathrm{~Hz}$ and $1.8 \mathrm{~Hz}$ was analyzed to understand the interactions between human and structure. Then, the finite element model of a large temporary grandstand was established to analyze the dynamic responses of structure when it was occupied by swaying crowds.

\section{Analytical Modeling of Human Swaying Force}

\subsection{Experimental Methodology and Swaying Load Formula.} Eight subjects were asked to participate in the swaying tests according to a rigorous assessment on the basis of their general state of health. And the basic information of participants is shown in Table 1. There are six males and two females with masses ranging from 48.5 to $115.7 \mathrm{~kg}$, their heights between 1.6 and $2.03 \mathrm{~m}$, and the ages ranging from 23 - to 38-year-olds. The side to side swaying forces were recorded using a Kistle9287CA (Switzerland, Kistle) $400 \times$ $600 \mathrm{~mm}^{2}$ triaxial force plate at a sample rate of $1 \mathrm{kHz}$ when an individual participant swaying movements in a standing position and guided by a constant metronome beat. Nine frequencies $1.0 \mathrm{~Hz}, 1.5 \mathrm{~Hz}, 2.0 \mathrm{~Hz}, 2.2 \mathrm{~Hz}, 2.5 \mathrm{~Hz}, 2.8 \mathrm{~Hz}$, $3.4 \mathrm{~Hz}$, and $3.6 \mathrm{~Hz}$ were inspired which are representative of that frequency range used in pop songs in assembly structure [22]. And the swaying frequencies are controlled by the constant metronome beat were called inspired frequencies; it is different in the frequencies of participants had swaying movements, and the aim of the inspired frequencies is to make the participant easy to follow the beat to sway.

Besides, a temporary grandstand-occupied twenty participants were tested when they were all swaying at it in a standing position and the inspired frequencies are the same as above nine frequencies. The twenty participants are males, and their mass ranges from 54 to $88 \mathrm{~kg}$, their height is between 1.62 and $1.84 \mathrm{~m}$, and their age ranges from 21 to 26 years. In order to follow the tempo of swaying more better for participants, not only every participant swayed at force plate but also swayed at temporary grandstand and they were asked to sway the hips to the left on one beat and then to the right on the next, just as shown in Figure 1 depicting that the crowd followed one beat at the time of $t_{1}$ and next beat at the time of $t_{3}$, so if participants completed a sway cycle, they will need to finish two beats, and the frequency $f_{\text {metronome }}$ inspired by metronome is twice the frequency of participant swaying $f$. All participants moved in a way that was natural to him or her according to the frequency of metronome.

For swaying forces model, a semiempirical formula was derived from the research of Nhleko et al. [12]:
$F_{\mathrm{ss}}(t)=\frac{2 H_{\mathrm{p}} \sin (\pi d)}{\pi} \sin (2 \pi f t) \pm \frac{2 H_{\mathrm{p}} \sin (3 \pi d)}{3 \pi} \sin (6 \pi f t)$,

where $F_{\mathrm{ss}}(t)$ stands for the dimensionless swaying force; $H_{\mathrm{p}}$ is the parameter of peak force ratio; $d$ is the parameter of time in $s$; $f$ is the frequency of swaying in $\mathrm{Hz}$; and $t$ is the duration time of swaying in s.

The unknown constraint parameters $H_{\mathrm{p}}, d$, and $f$ will be investigated and solved directly from the experimental data.

2.2. Constraint Parameters. All measured data were filtered digitally to remove frequency components when they were greater than $10 \mathrm{~Hz}$. In a typical swaying test, the swaying forces of the 2nd participant and 3rd participant which were recorded by force plate are shown in Figure 2, respectively. And the force curves of time history show a certain periodicity with positive values and negative values.

In order to reveal the dominant shape of each swaying force curve, the continuous curve of force is separated into individual impulses at intervals corresponding to zero crossing as shown in Figure 2. And then the results of 1st, $2 \mathrm{nd}, 3 \mathrm{rd}, 7 \mathrm{th}$, and 8 th participant are shown in Figures 3(a)-3(e), and Figure 3(f) shows the force curves of 1 st and 2 nd in the same window.

Two types of impulse shapes were observed, which are similar to the results of the researches [11, 12]. So, it is considered that the gathered data are reasonable to be simulated by Equation (1), and the minus sign is used when swaying frequencies are less than or equal to $1.0 \mathrm{~Hz}$, while the plus sign is used when swaying frequencies are higher than $1.0 \mathrm{~Hz}$. Typical values for the parameters $d$ are given in Table 2 at different swaying frequencies, which according to the experience of the authors in this paper.

Values of $H_{p}$ are evaluated on the basis of experimental data, and 2600 of values are obtained with $H_{\mathrm{p}}$ ranging from 0.08 to 0.39 . As a whole sample, the sampling interval is 0.02 , and then the number and frequency are shown in Table 3. So, the histogram of frequency is shown in Figure 4; meanwhile, the lognormal distribution curve is chosen as the probability density function of $H_{\mathrm{p}}$ which also is shown in Figure 4. And the function is given in Equation (2), where the mean value is -1.6890 and the standard deviation $(\mathrm{sd})$ is 0.3822 .

$$
f\left(H_{\mathrm{p}}\right)=\frac{1}{0.3822 x \sqrt{2 \pi}} \times e^{-\left(\left(\ln H_{\mathrm{p}}+1.6890\right)^{2} /\left(2 \times 0.3822^{2}\right)\right)} .
$$

Then the parameter $H_{\mathrm{p}}$ can be represented by the Monte Carlo method with Equation (2), just like using the program command lognrnd $(\mathrm{mu}=-1.6890$, sigma $=0.3822, n, 1)$ of mathematical software MATLAB to simulate $n$ numbers of $H_{\mathrm{p}}$.

Although participants can follow the tempo which was inspired by metronome to sway, it is clear that swaying is a typical stochastic process due to intrasubject variability and intersubject variability, and the period of each sway cycle which participants completed is different from each other. So, the times between any two successive zero crossing points were obtained to evaluate the inverse of the resulting frequencies. The frequency data were analyzed by 
TABLE 1: Fundamental physics information of participants.

\begin{tabular}{lcccccccc}
\hline Number & 1 & 2 & 3 & 4 & 5 & 6 & 7 & 8 \\
\hline Mass (kg) & 110.5 & 73.5 & 59.5 & 55.7 & 81.4 & 48.5 & 51.3 \\
Height (m) & 1.90 & 1.80 & 1.78 & 1.70 & 1.73 & 1.62 & 1.60 \\
Old (year) & 26 & 26 & 27 & 23 & 28 & 26 & 2.03 \\
Sex & Male & Male & Male & Male & Male & Female & Female & 38 \\
\hline
\end{tabular}
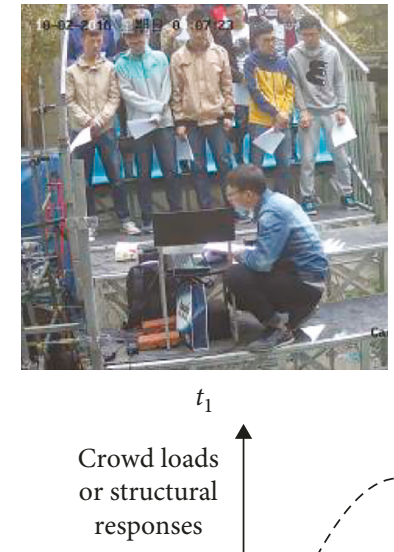

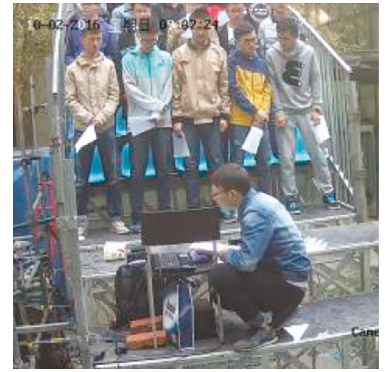

$t_{2}$

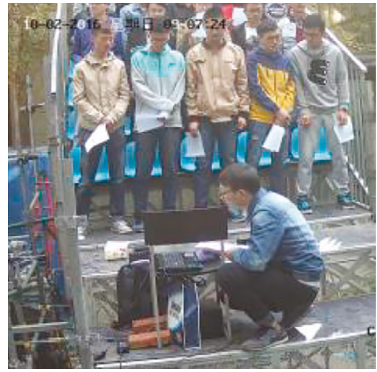

$t_{3}$

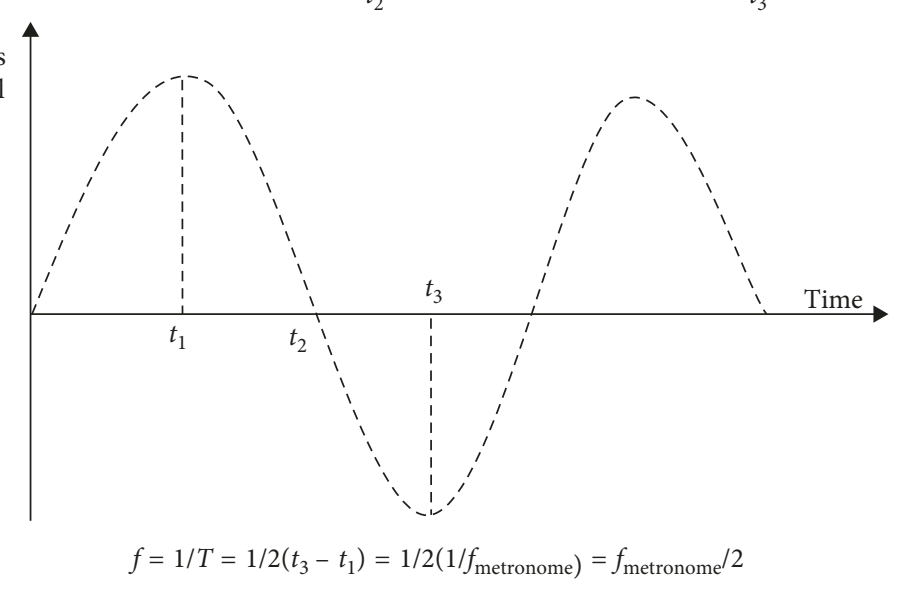

FIGURE 1: The relationship between metronome frequency and crowd swaying frequency.
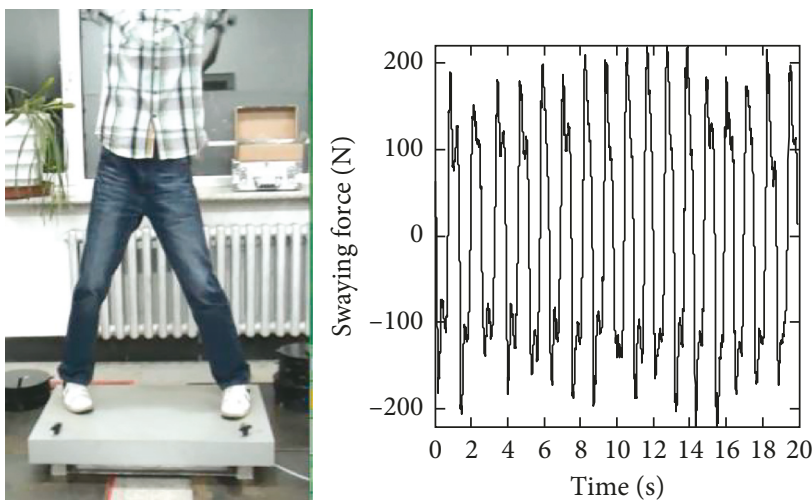

(a)

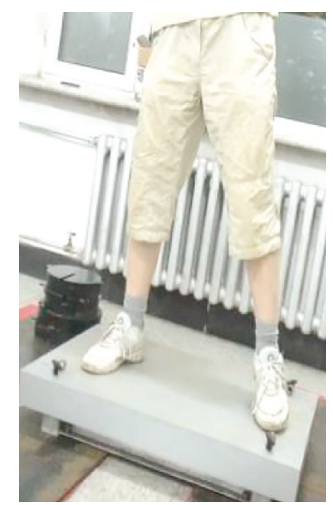

FIgURE 2: Swaying test and load curve. (a) 2nd participant swaying. (b) 3rd participant swaying.

Kolmogorov-Smirnov test (K-S test) and it was found that they fitted the normal distribution, as shown in Figure 5 which gave the results of inspired frequency is $3.0 \mathrm{~Hz}, 3.4 \mathrm{~Hz}$, and $3.6 \mathrm{~Hz}$, respectively. Then, the relevant parameters such mean value, standard deviation, and interval censoring for not only the three frequencies but also the rest of frequencies are shown in Table 4. According to these parameters, the simulated $f$ can represent $n$ numbers of $f$ by the program command normrnd (mean, sd, $n, 1$ ) of mathematical software MATLAB.

So, according to the above given parameters $H_{\mathrm{p}}, d$, and $f$, the swaying forces can be represented by Equation (1). In 


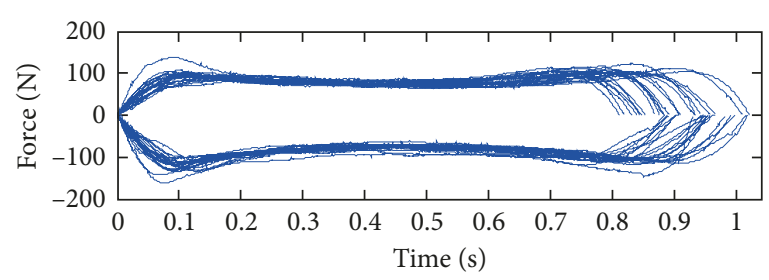

(a)

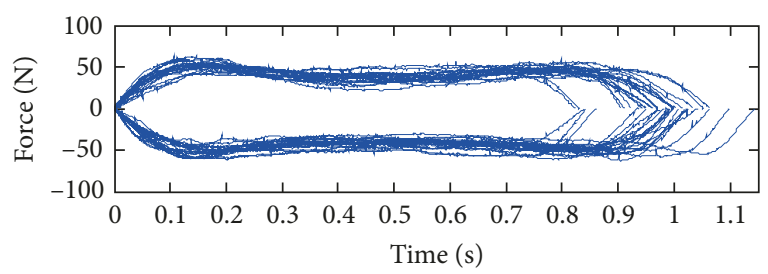

(c)

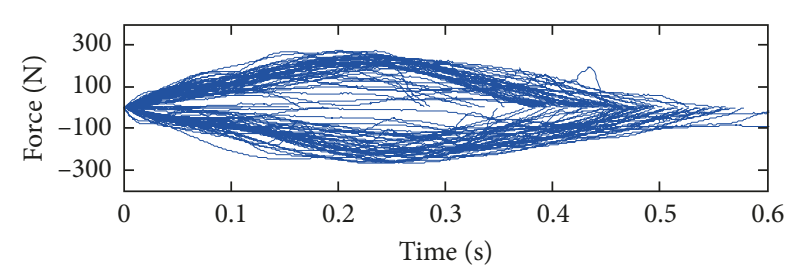

(e)

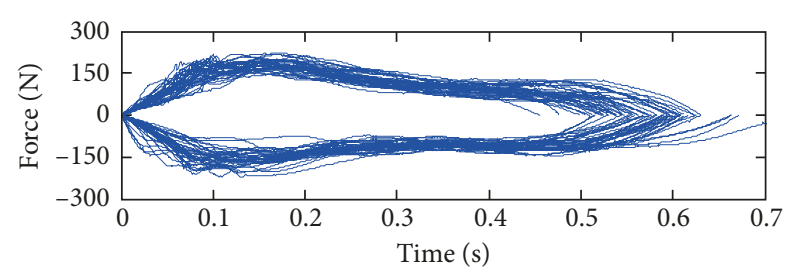

(b)

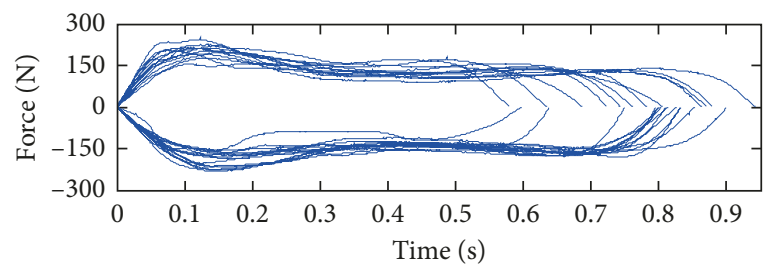

(d)

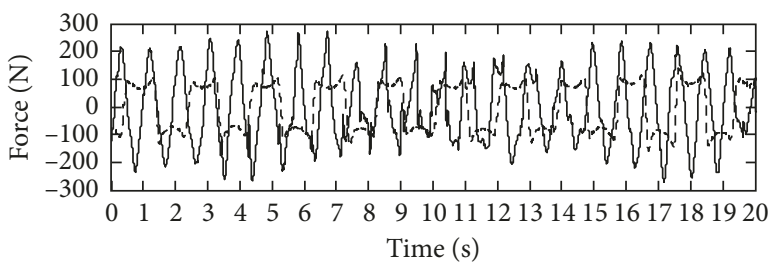

---2 th

- 1th

(f)

Figure 3: The single swaying load.

TABle 2: The value of parameter $d$.

\begin{tabular}{lccccccccc}
\hline Sway frequency $f(\mathrm{~Hz})$ & $\leq 1$ & 1.1 & 1.2 & 1.3 & 1.4 & 1.5 & 1.6 & 1.7 & 1.8 \\
\hline$d$ & $1 / 3 f$ & $1 / 2.9 f$ & $1 / 2.7 f$ & $1 / 2.5 f$ & $1 / 2.3 f$ & $1 / 2.1 f$ & $1 / 1.9 f$ & $1 / 1.7 f$ & $1 / 1.6 f$ \\
\hline
\end{tabular}

Table 3: The frequency of swaying load peak ratio.

\begin{tabular}{lcc}
\hline Zone & Number $n_{i}$ & Frequency $n_{i} / n$ \\
\hline $0.07 \sim 0.09$ & 20 & 0.01 \\
$0.09 \sim 0.11$ & 160 & 0.06 \\
$0.11 \sim 0.13$ & 270 & 0.10 \\
$0.13 \sim 0.15$ & 150 & 0.06 \\
$0.15 \sim 0.17$ & 350 & 0.13 \\
$0.17 \sim 0.19$ & 220 & 0.08 \\
$0.19 \sim 0.21$ & 320 & 0.12 \\
$0.21 \sim 0.23$ & 230 & 0.09 \\
$0.23 \sim 0.25$ & 180 & 0.07 \\
$0.25 \sim 0.27$ & 110 & 0.04 \\
$0.27 \sim 0.29$ & 140 & 0.05 \\
$0.29 \sim 0.31$ & 130 & 0.05 \\
$0.31 \sim 0.33$ & 140 & 0.05 \\
$0.33 \sim 0.35$ & 80 & 0.03 \\
$0.35 \sim 0.37$ & 30 & 0.01 \\
$0.37 \sim 0.39$ & 70 & 0.03 \\
$\sum$ & $n=2600$ & 1.00 \\
\hline
\end{tabular}

order to compare the forces generated by the application of the Equation (1) and measurements, Figure 6 shows the curve of the swaying frequency $1.0 \mathrm{~Hz}$ and $3.0 \mathrm{~Hz}$ at the time domain analysis and the results of frequency domain analysis, and it is clear that the type of the simulated curves are similar to the test curves and also the contents of frequency are similar to each other.

2.3. Crowd Swaying Force Model. The forces of crowd swayed at a temporary grandstand are different in the measured data of twenty single participants swayed at force plate because different persons will have different swaying rhythms. It is hard to capture the each individual swaying force of crowd, but the cycle-by-cycle variation of the frequency and period of the crowd swaying can be analyzed by the structural dynamic response, such as Figure 7 depicts the structural lateral displacement of point L9 (Figure 8(c)) when crowd had swayed at $1.0 \mathrm{~Hz}$ and $3.0 \mathrm{~Hz}$, respectively. Two types of force impulses are also observed from the displacements of time history, and these impulses represent two natural states for crowd swaying side to side in lower and higher frequency, respectively.

On the basis of these structural lateral displacement curves, the each crowd swaying frequency at inspired frequency which controlled by metronome is investigated and shown in Table 5. This table gives the number of measured data and mean value of period, frequency, and its standard 


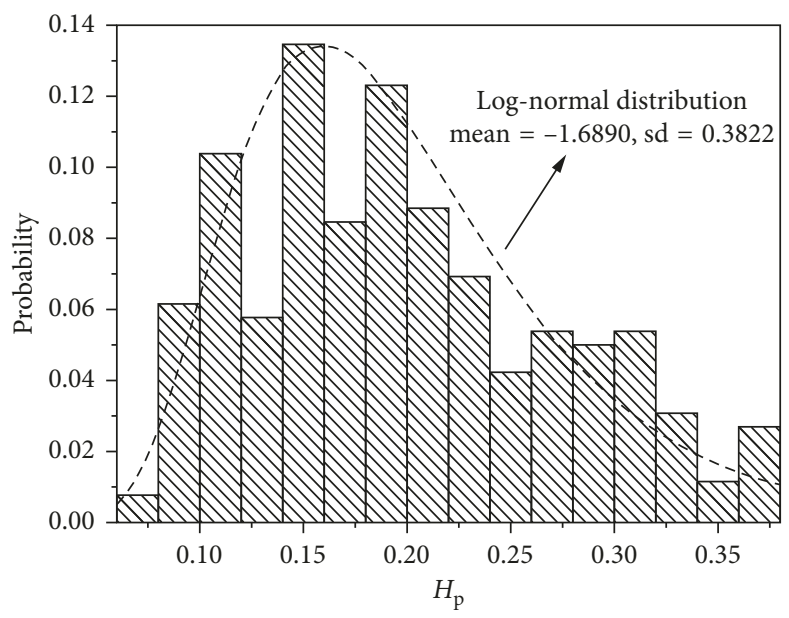

FIgURE 4: The probability of $H_{\mathrm{p}}$ and lognormal distribution curve.

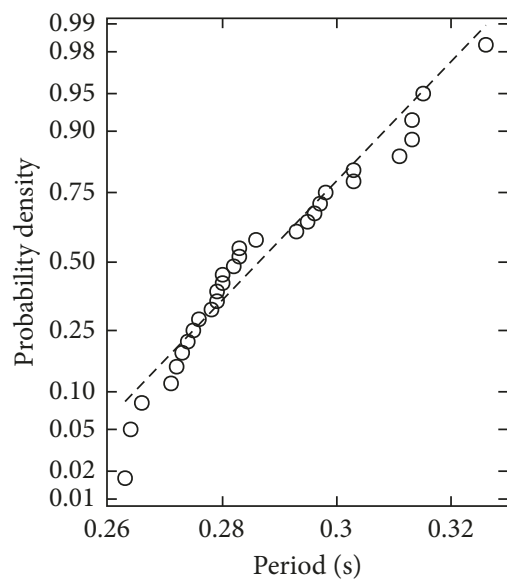

(a)

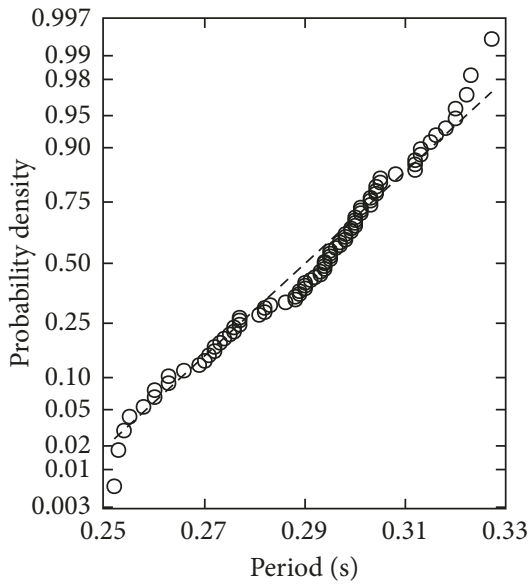

(b)

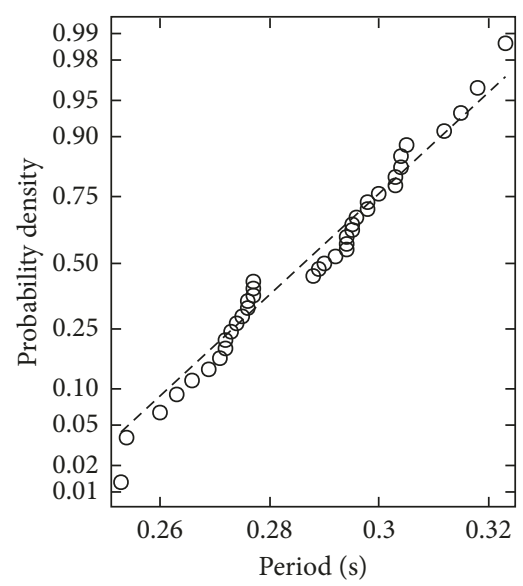

(c)

FIgURE 5: Normal distribution test of swaying periods. (a) $3.0 \mathrm{~Hz}$, (b) $3.4 \mathrm{~Hz}$, and (c) $3.6 \mathrm{~Hz}$.

TABle 4: The parameters of normal distribution of swaying frequencies.

\begin{tabular}{lccc}
\hline $\begin{array}{l}\text { Crowd swaying } \\
\text { frequency } f\end{array}$ & Mean & $\begin{array}{c}\text { Standard } \\
\text { deviation }\end{array}$ & $\begin{array}{c}\text { Interval } \\
\text { censoring }\end{array}$ \\
\hline 0.50 & 0.550 & 0.110 & {$[0.47,0.55]$} \\
0.75 & 0.785 & 0.100 & {$[0.74,0.81]$} \\
1.00 & 1.010 & 0.094 & {$[0.98,1.02]$} \\
1.10 & 1.085 & 0.085 & {$[1.06,1.12]$} \\
1.25 & 1.240 & 0.060 & {$[1.21,1.27]$} \\
1.40 & 1.395 & 0.062 & {$[1.38,1.42]$} \\
1.50 & 1.495 & 0.026 & {$[1.47,1.52]$} \\
1.70 & 1.720 & 0.018 & {$[1.68,1.73]$} \\
1.80 & 1.790 & 0.047 & {$[1.76,1.82]$} \\
\hline
\end{tabular}

deviation. It is found that most of the swaying frequencies of the crowd are lower than inspired frequencies, only when crowd followed by the swaying inspired frequency $3.0 \mathrm{~Hz}$ and the measured data reflected the crowd swaying frequency is $3.48 \mathrm{~Hz}$ These consistent phenomena indicate that participants have their own rhythm to sway, and the leading and legging situation present in an asynchronous crowd swaying, so it is the reason of lack of synchronization. When the standard deviation is not more than 0.1 , it means that the crowd can cooperatively sway.

In order to quantitatively analyze the influence of group effect in the synchronized component of crowd swaying load, a parameter $C$ was introduced and calculated by

$$
\begin{aligned}
C & =1-\left|\frac{T_{\text {Theory }}-T_{\text {Test }}}{T_{\text {Test }}}\right|, \\
T_{\text {Theory }} & =\frac{1}{f_{\text {metronome }}},
\end{aligned}
$$

where $f_{\text {metronome }}$ is the inspired frequencies as explained in Section 2.1 and $T_{\text {Test }}$ is the mean of measured data from Table 5.

The distribution of $C$ values plotted against inspired frequencies is shown in Figure 9(a), it falls to the lowest value 0.58 when the frequency is $2.0 \mathrm{~Hz}$ and then increases to the highest value 0.95 when the frequency is $3.4 \mathrm{~Hz}$ and $3.6 \mathrm{~Hz}$. It 

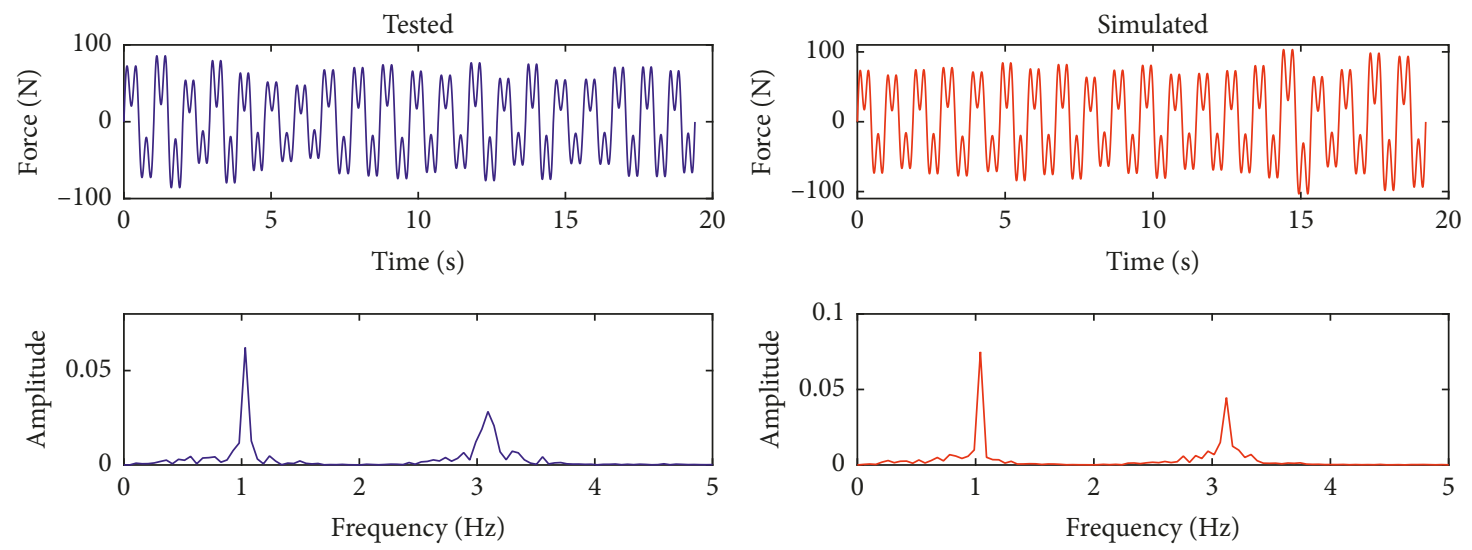

(a)
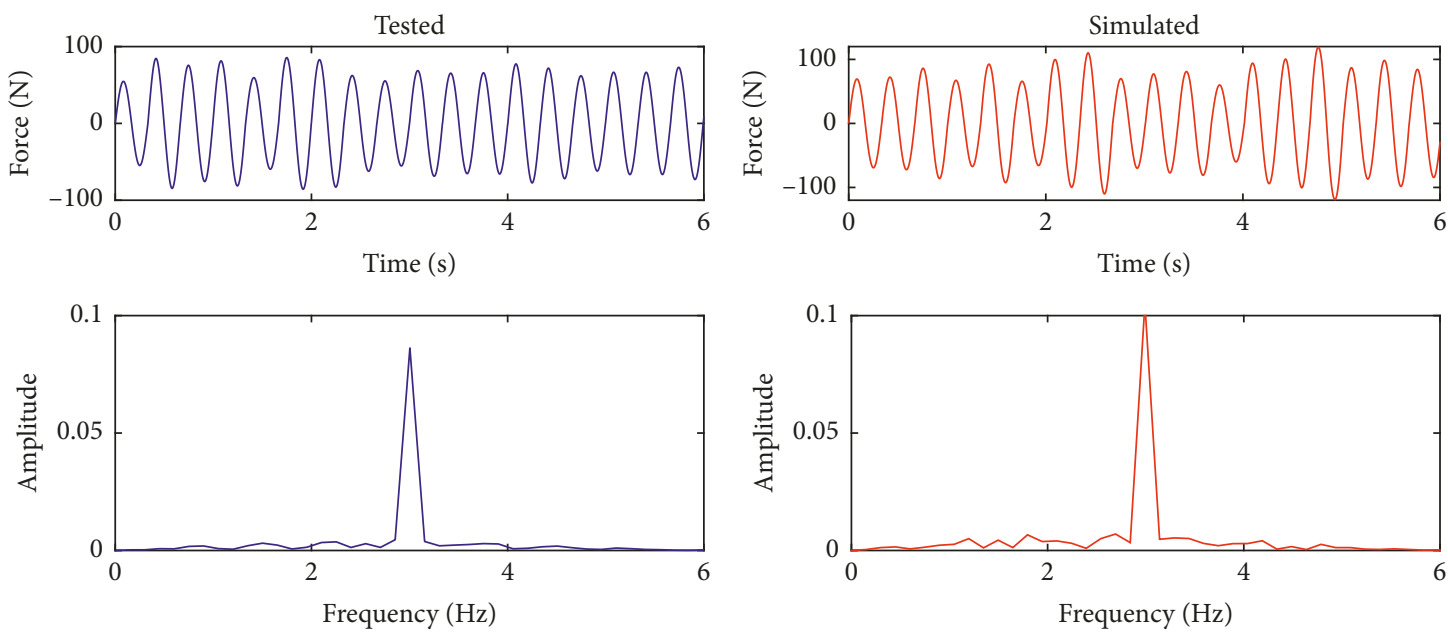

(b)

FIGURE 6: Compared measures with simulated force signals at time and frequency domain. (a) The results of swaying frequency $1.0 \mathrm{~Hz}$ and (b) the results of swaying frequency $3.0 \mathrm{~Hz}$.

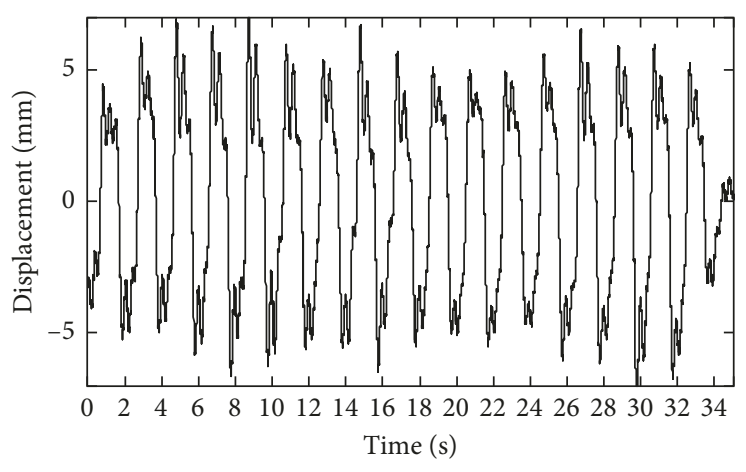

(a)

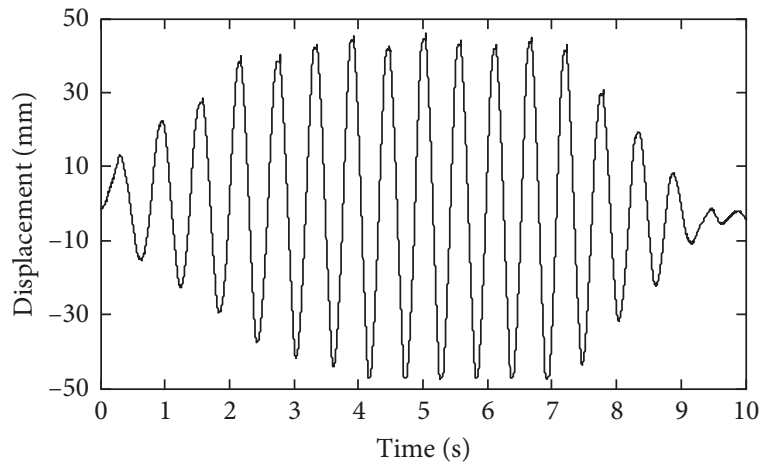

(b)

Figure 7: The structural lateral displacement of twenty persons swaying at (a) $1.0 \mathrm{~Hz}$ and (b) $3.0 \mathrm{~Hz}$.

is concluded that the crowd swaying synchronism is influenced by frequency and reflected that crowd would be difficult to sway at $2.0 \mathrm{~Hz}$ and easily to sway when frequency is greater than $2.2 \mathrm{~Hz}$. But, it is noticeable that when the crowd swayed at $3.6 \mathrm{~Hz}$, the $C$ value no longer increases, and when enquiring these participants and observing the experiment video, they said it is very difficult to sway at $3.6 \mathrm{~Hz}$ and some of crowd had to hold guardrail to help them sway. So, the swaying frequency of crowd may be available between $1.0 \mathrm{~Hz}$ and $1.7 \mathrm{~Hz}$. Then the linear relationship between crowd swaying frequency and $C$ value is shown in Figure 9(b), and the fitting curve is given in the following equation: 


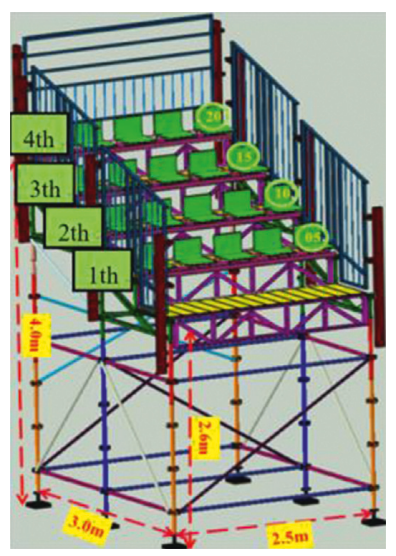

(a)

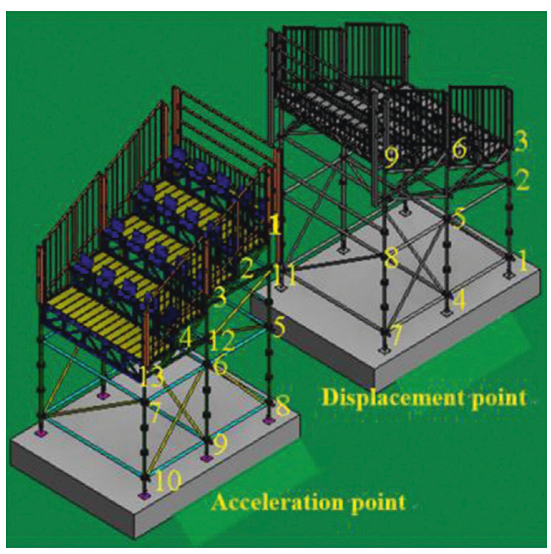

(b)

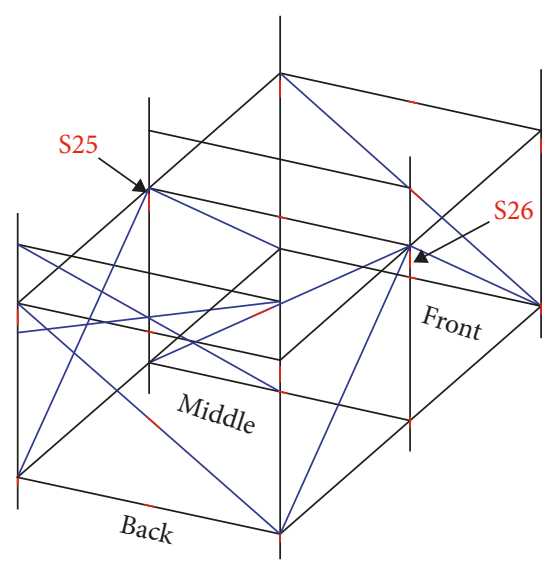

(c)

FIgURE 8: The test structure and test points. (a) The size of structure. (b) Acceleration and displacement point. (c) Strain point.

TABLE 5: Comparisons of metronome frequencies and crowd response frequencies.

\begin{tabular}{lcccc}
\hline Inspired frequency $(\mathrm{Hz})$ & Number & Mean value of period (s) & Mean value of frequency $(\mathrm{Hz})$ & Standard deviation \\
\hline 1.0 & 36 & 0.994 & 1.01 & 0.03 \\
1.5 & 27 & 0.699 & 1.43 & 0.08 \\
2.0 & 29 & 0.710 & 1.41 & 0.07 \\
2.2 & 28 & 0.570 & 2.09 & 0.06 \\
2.5 & 43 & 0.479 & 2.55 & 0.06 \\
2.8 & 43 & 0.392 & 3.48 & 0.07 \\
3.0 & 31 & 0.287 & 3.33 & 0.03 \\
3.4 & 45 & 0.300 & 3.57 & 0.04 \\
3.6 & 41 & 0.280 & & 0.02 \\
\hline
\end{tabular}

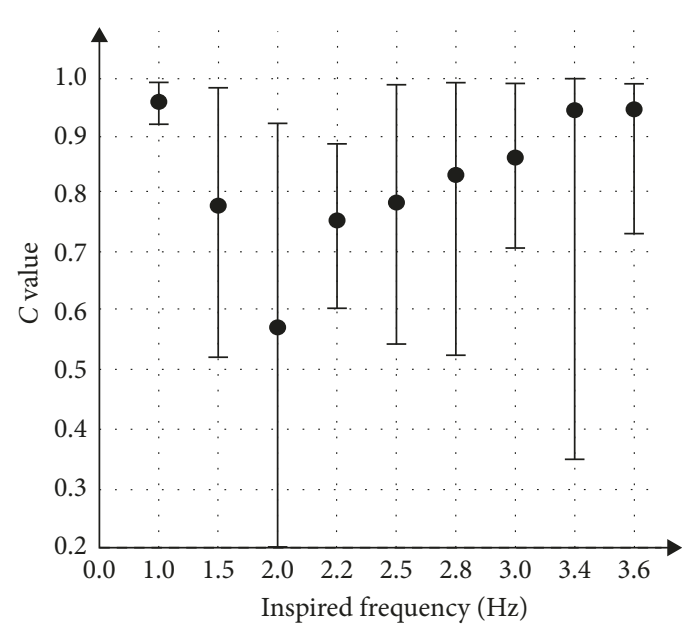

(a)

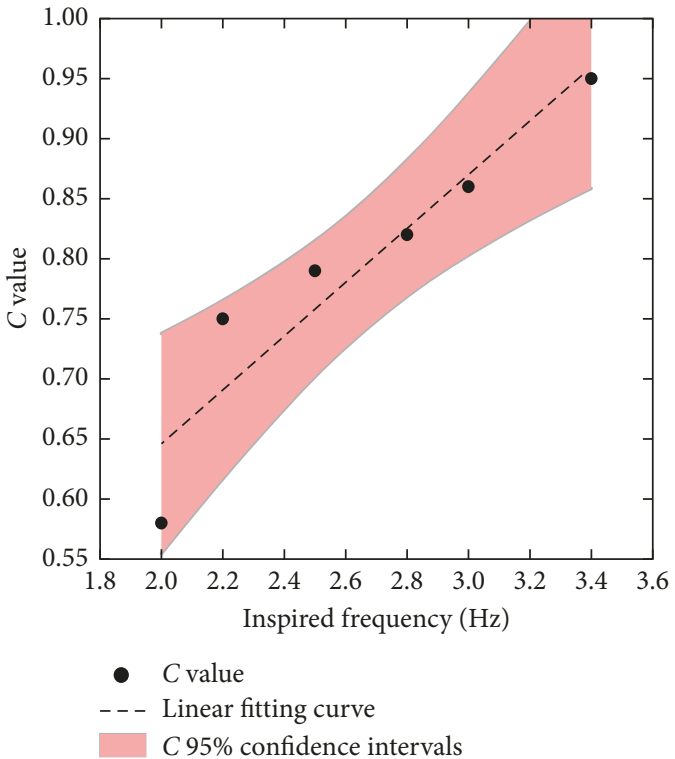

(b)

FIgURE 9: The relationship between inspired frequency and $C$ value. (a) Analysis of crowd swaying synchronization and (b) the linear fitting curve.

$$
C=0.2239 \times 2 f+0.1981
$$

where $f$ is the crowd swaying frequency.

The parameter $C$ of $95 \%$ confidence intervals are calculated and given in Table 6. So, based on Equation (1) with constraint parameters $H_{\mathrm{p}}, d$, and $f$, the swaying force of single person can be regenerated, and the crowd swaying forces can also be simulated by Equation (1) according to the number of crowd, and these simulated curves need to calculate the $C$ value and conform to the limits in Table 6 . 
TABLE 6: $C$ values of $95 \%$ confidence intervals.

\begin{tabular}{lccccrr}
\hline$f(\mathrm{~Hz})$ & 1.0 & 1.1 & 1.25 & 1.4 & 1.5 & 1.7 and 1.8 \\
\hline Intervals & {$[0.55,0.73]$} & {$[0.62,0.76]$} & {$[0.70,0.81]$} & {$[0.76,0.88]$} & {$[0.80,0.93]$} & {$[0.80,0.96]$} \\
\hline
\end{tabular}

\section{Lateral Dynamic Performance and Response of Structure}

In order to investigate the lateral dynamic responses of temporary grandstand, a temporary grandstand that occupied twenty persons was erected in the outside, and the bottom of base jacks of the test rig was only put on the ground without bolted and/or tied connection, and the structure and the arrangement of the bracing elements are often used in practical projects. Table 7 depicts the members of test TDG and its weight and structural schematic. The structure is comprised of nine kinds of members, which are shown in schematic. There are four row seats and five column seats that accommodate 20 persons. Seating system includes guardrails, seat braces, seat beams, and decks and stepped frames. Hollow bar of the supporting system includes standards, ledgers, bay bracings, and base jacks. The type of connection employed to assemble the hollow bars is plug-pin joint, which is also shown in Table 1, and the deck laps on the seat braces and triangular stepped frame. The weight of empty structure is $912.98 \mathrm{~kg}$.

In Figure 8(a), the main dimensions of test structure are height of front row $(2.6 \mathrm{~m})$, back $(4.0 \mathrm{~m})$, left-to-right span $(2.5 \mathrm{~m})$, and front-to-back span (up to $3.0 \mathrm{~m}$ ). Thirteen accelerometer points A1-A13 and nine linear variable differential transformers (L1-L9) are shown in Figure 8(b). The accelerator point A1-A4 measured the responses of structural seating system. The strains of structure members are measured, and the position of points is marked in red as shown in Figure 8(c). Data were collected at a sampling frequency of $1 \mathrm{kHz}$ using IMC data acquisition software carrying a built-in antialias filter (German model IMC CRONOS compact-400-08 with robust housing) and a DH5922 (Dong Hua, China). The recorded curves were digitally filtered with a frequency content of up to $25 \mathrm{~Hz}$ in order to minimize the effect of background noise.

3.1. Structural Natural Frequency and Damping. The lateral (left-to-right) modes are usually the most important ones for temporary grandstands [9] although it may not always be the fundamental mode of the whole grandstand which is critical, and some codes and guidelines have given the limits of frequency, i.e., IStructE [23-25] recommends that if the lateral natural frequency is lower than $4.0 \mathrm{~Hz}$, it is needed to analyze the structural dynamic responses. So, in this paper, the structure was tested by a shaking table with sin sweep and white-noise experiments in laboratory besides the human traction test in which that structure was pulled by a rope which tied in the top of structure and then suddenly let go to measure the structural decay curve. The aim of these experiments is to investigate the natural frequency of test structure.

When the structural dynamic response curves of time history of all measure points were analyzed, it is found that only the data of A1-A4 and L3, L6, and L9 points had obvious decay phenomenon. And the results of acceleration decaying curves of A1-A4 and frequency domain analysis are shown in Figure 10(a) of the human traction test, and there is only one noticeable amplitude and the corresponding frequency is $2.7 \mathrm{~Hz}$, and also the results of sin sweep test shown in Figure 10(b) indicate the natural frequency is $2.5 \mathrm{~Hz}$. While for the results of the whitenoise test, the first-order frequency is about $3.5 \mathrm{~Hz}$, and the highorder frequencies are also obtained (Figure 10(c)), such as the second-order frequency about $7.2 \mathrm{~Hz}$ and the third-order frequency about $12.2 \mathrm{~Hz}$. It can be seen that the structure has a lower frequency, especially for the results of the measure points A1 to A4 which stands for the dynamic performance of seating systems (Table 7), and the frequency is lower than the limits of some guidelines. The first-order frequency is close to the frequency of crowd swaying and the crowd can directly interact with the seating system of structure, so it may be the reason why the structure is vulnerable to lateral vibration under crowd loads.

And, in order to better understand the influence of crowd for structural frequency, the decay curves of structural dynamic responses when it occupied twenty persons who swayed after were recorded, just as the displacement curve of L6 and L9 shown in Figure 11, and the frequency domain analysis is also given and there is only one amplitude and the frequency is $1.6 \mathrm{~Hz}$.

It is a feasible method to determine the damping ratio by Equation (5) with decay curve. Then, the damping ratio $7.3 \%$ of empty structure is obtained, and this value is high than the normal value $5 \%$ of the steel structure; this may be due to the gaps of structural members can provide fraction which contributes to damping when structure has vibration. The damping ratio $48 \%$ of structure occupied crowd which means crowd can effective improve the damping of occupied structure

$$
\begin{aligned}
& \zeta=\frac{1}{2 \pi j} \ln \frac{\ddot{x}_{i}}{\ddot{x}_{i+j}}, \\
& \zeta=\frac{1}{2 \pi j} \ln \frac{x_{i}}{x_{i+j}},
\end{aligned}
$$

where $x_{i}, \ddot{x}_{i}, x_{i+j}, \ddot{x}_{i+j}$ is $i$ th and $i+j$ th peak value of displacement and acceleration.

So, according to the decrease of frequency and increase of damping ratio when the structure occupied crowd, the human as mass-stiffness-damping system can be verified again.

3.2. Structural Dynamic Responses. There are eleven conditions about different locations of swaying crowd, including all participants and different rows of crowd when they are seated and/or standing swaying, and they followed the inspired frequencies spanning the range $1.0-3.6 \mathrm{~Hz}$, which the details are shown in Table 8. The structural strains, displacements, and accelerations of measurement points are analyzed, and also the domain analysis of structure force oscillation is investigated in the contents. 
TABle 7: Test structure.

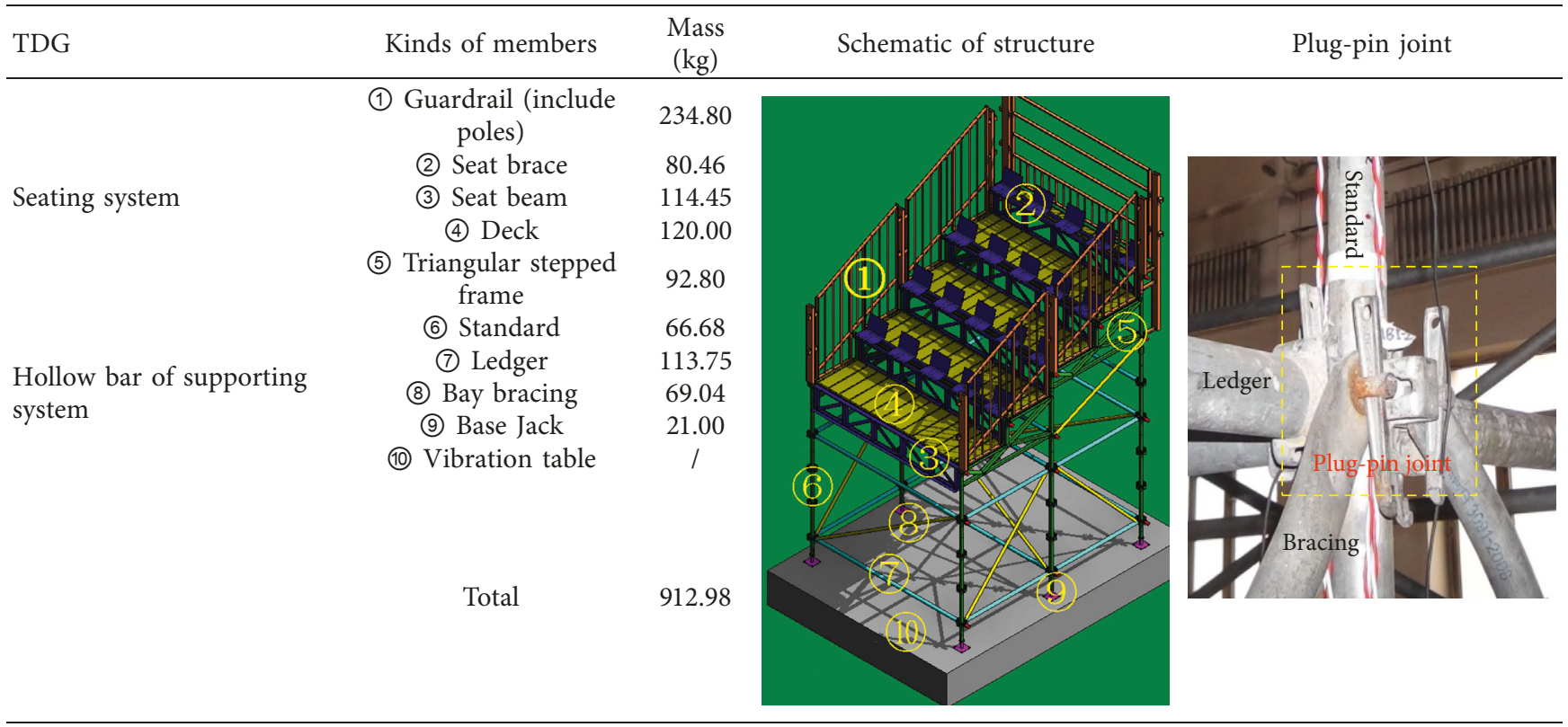
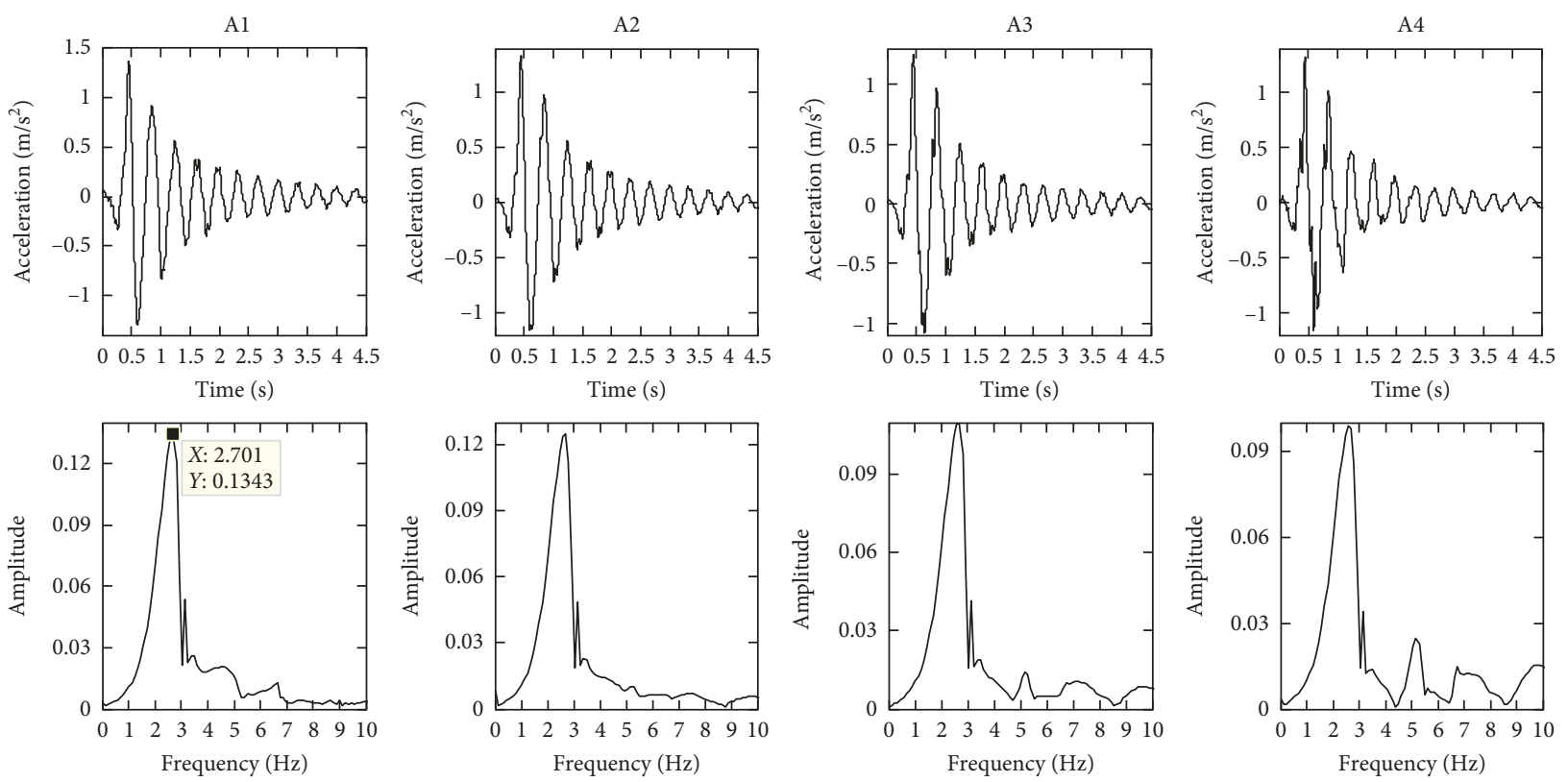

(a)

Figure 10: Continued. 

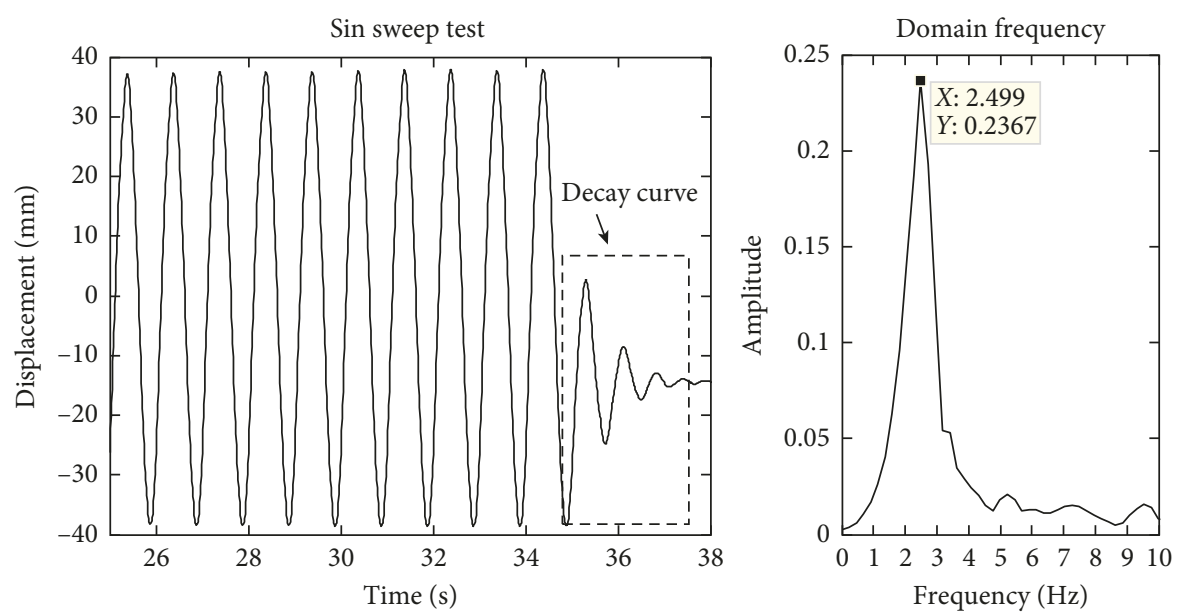

(b)
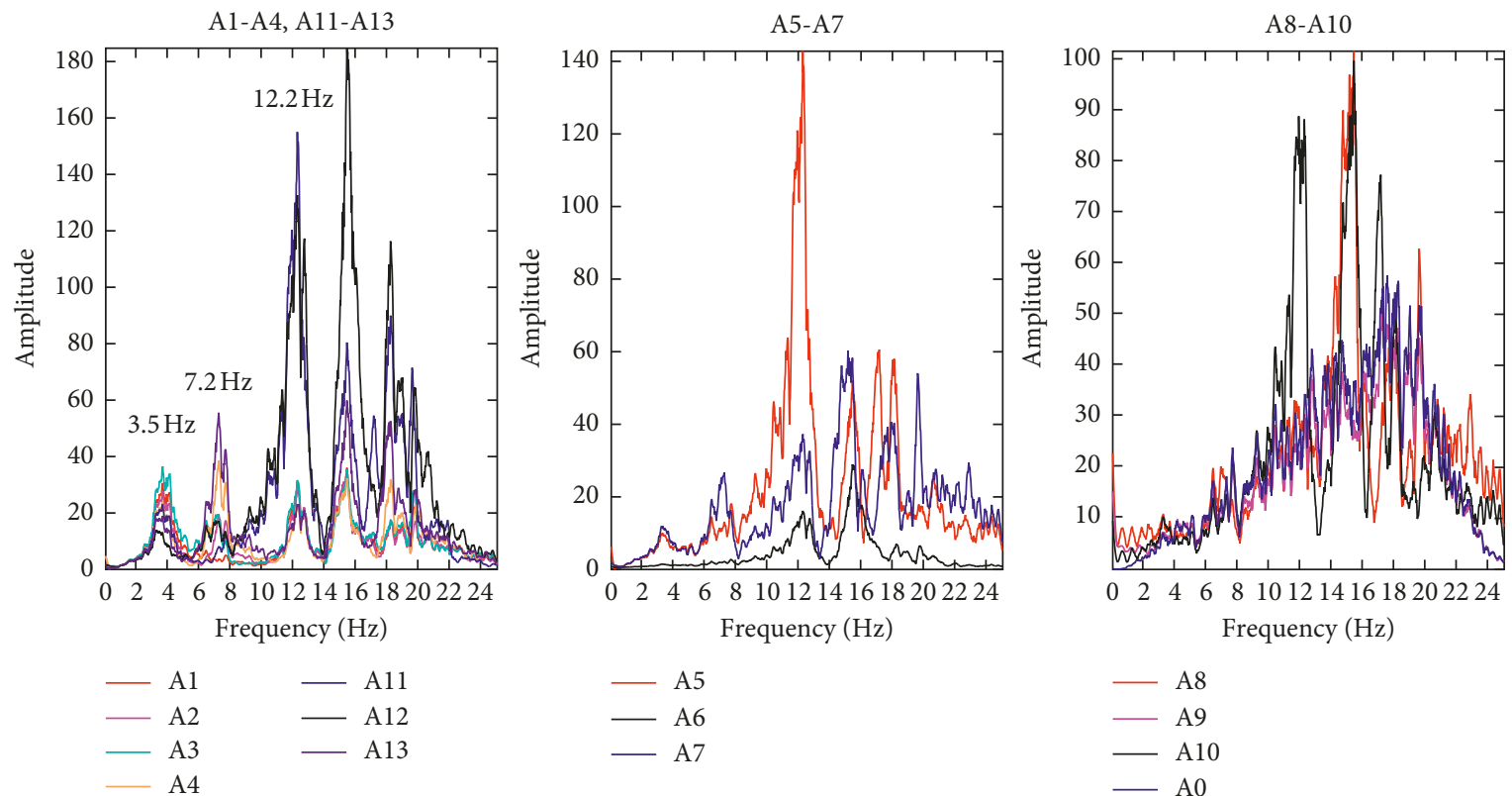

(c)

FIGURE 10: The lateral natural frequencies of test structure. (a) Human traction test results. (b) Sin sweep test results. (c) White-noise test result.

The results show that points S25 and S26 (Figure 10(c)) have the max value in all the strain measurement points, so the curves of time history when all participants swayed at nine frequencies are shown in Figure 12. Not only the standing crowd (Figure 13(a)) but also the seated crowd (Figure 13(b)) can induce structure has near-period strain curve when crowd followed the swaying inspired frequencies especially it is higher than $3.0 \mathrm{~Hz}$. Then the peak value of each curve in all conditions is collected and plotted against crowd swaying frequency, which is shown in Figure 12. All the scatted data reflect that the strain has a nonlinear increase with crowd frequency, and the max value is about 1000 microstrains when crowd swayed in standing, so the max stress is $205 \mathrm{MPa}$. The interesting thing is that when the first row five persons are static in seated and other rows persons are swaying in standing, the structural stains (filled dot in Figure 12(a)) are larger than those when all standing persons swayed, whereas when the first five persons are static in standing, the results are just the other way. For seated crowd sway, the results in Figure 12(b) show that more seated persons had swayed and more strain is induced in the structure. But, it can be concluded that the standing crowd can induce more strain than the seated crowd when they have swaying activities.

For analyzing the lateral displacement of structure, the peak values of curves of L9 point are plotted against crowd swaying frequency and are shown in Figure 14, it is shown that there is a nonlinear relationship between peak values and crowd swaying frequencies. The scattered data show that more persons had sway and more big displacement is induced in structure. What is more, the max value is $57 \mathrm{~mm}$ when all the standing persons are swaying at structure, which means crowds generate periodic swaying forces because rhythmic activities can cause significant lateral displacement even the 

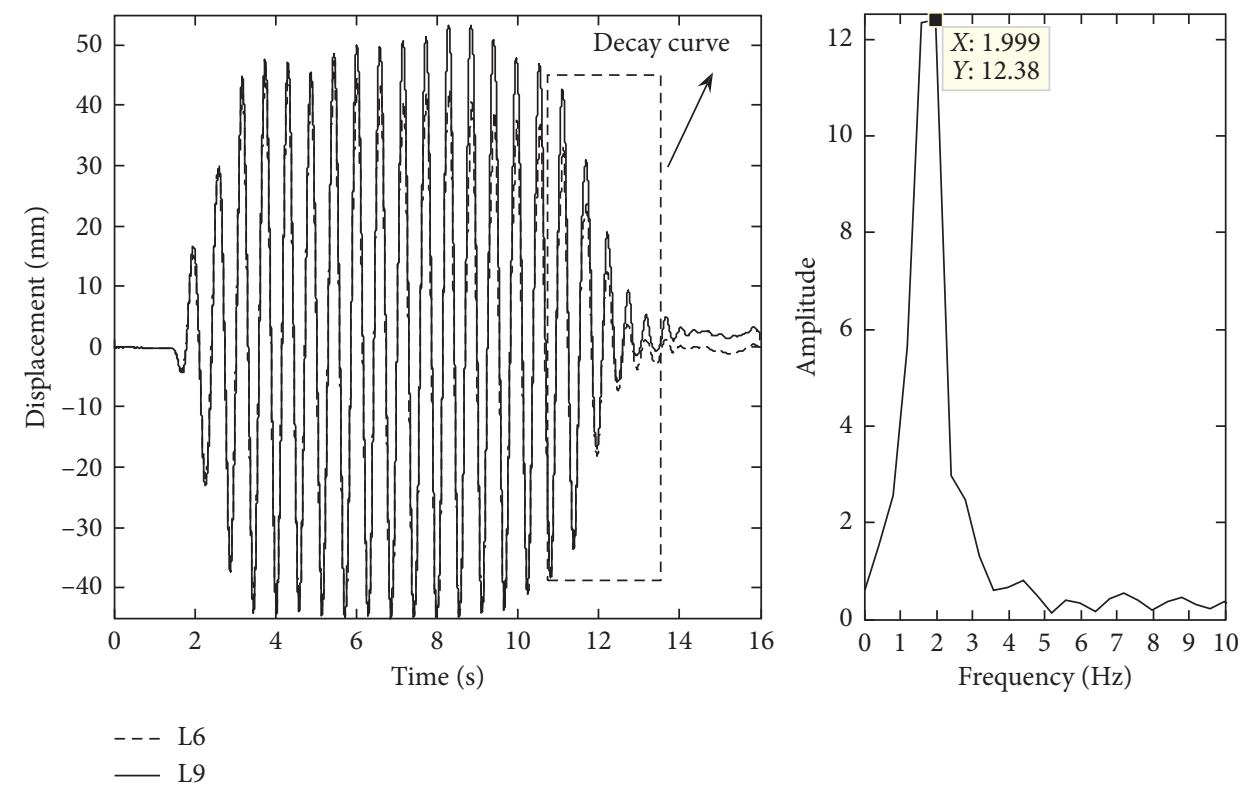

FIGURE 11: The natural frequency of structure when the standing person is swaying.

TABLE 8: Conditions of crowd swayed at structure.

\begin{tabular}{|c|c|c|}
\hline $\begin{array}{l}\text { Test } \\
\text { condition } \\
\text { number } \\
\end{array}$ & Test conditions & $\begin{array}{l}\text { Excitation swaying } \\
\text { frequency }(\mathrm{Hz})\end{array}$ \\
\hline 1 & $\begin{array}{l}\text { All standing persons } \\
\text { swaying }\end{array}$ & $\begin{array}{c}0.5,0.75,1.0,1.1, \\
1.25,1.4,1.5,1.7,1.8\end{array}$ \\
\hline 2 & All seated persons swaying & $\begin{array}{c}0.5,0.75,1.0,1.1 \\
1.25,1.4,1.5,1.7,1.8\end{array}$ \\
\hline 3 & $\begin{array}{l}\text { Number } 6-20 \text { person } \\
\text { standing swaying, } 1-5 \\
\text { person seated }\end{array}$ & $\begin{array}{c}0.5,0.75,1.0,1.1 \\
1.25,1.4\end{array}$ \\
\hline 4 & $\begin{array}{l}\text { Number } 11-20 \text { person } \\
\text { standing swaying, } 1-10 \\
\text { person seated }\end{array}$ & $\begin{array}{c}0.5,0.75,1.0,1.1 \\
1.25,1.4\end{array}$ \\
\hline 5 & $\begin{array}{l}\text { Number } 16-20 \text { person } \\
\text { standing swaying, } 1-15 \\
\text { person seated }\end{array}$ & $\begin{array}{c}0.5,0.75,1.0,1.1 \\
1.25,1.4\end{array}$ \\
\hline 6 & $\begin{array}{l}\text { Number } 6-20 \text { person } \\
\text { standing swaying, } 1-5 \\
\text { person standing }\end{array}$ & $\begin{array}{c}0.5,0.75,1.0,1.1 \\
1.25,1.4\end{array}$ \\
\hline 7 & $\begin{array}{l}\text { Number } 11-20 \text { person } \\
\text { standing swaying, } 1-10 \\
\text { person standing }\end{array}$ & $\begin{array}{c}0.5,0.75,1.0,1.1 \\
1.25,1.4\end{array}$ \\
\hline 8 & $\begin{array}{l}\text { Number } 16-20 \text { person } \\
\text { standing swaying, } 1-15 \\
\text { person standing }\end{array}$ & $\begin{array}{c}0.5,0.75,1.0,1.1 \\
1.25,1.4\end{array}$ \\
\hline 9 & $\begin{array}{l}\text { Number } 6-20 \text { person seated } \\
\text { swaying, } 1-5 \text { person seated }\end{array}$ & $\begin{array}{l}0.5,0.75,1.0,1.1 \\
1.25,1.4\end{array}$ \\
\hline 10 & $\begin{array}{l}\text { Number } 11-20 \text { person } \\
\text { seated swaying, } 1-10 \\
\text { person seated }\end{array}$ & $\begin{array}{c}0.5,0.75,1.0,1.1 \\
1.25,1.4\end{array}$ \\
\hline 11 & $\begin{array}{l}\text { Number } 16-20 \text { person } \\
\text { seated swaying, } 1-15 \text { person } \\
\text { seated }\end{array}$ & $\begin{array}{c}0.5,0.75,1.0,1.1 \\
1.25,1.4\end{array}$ \\
\hline
\end{tabular}

structure is safe. It also can be concluded that standing crowd can induce more displacement than the seated crowd when they have swaying activities.
The frequency domain of structure when it was swayed by crowd is analyzed and shown in Figure 15. It is well known that this frequency is the frequency of crowd swaying forces, there are significant peak values at the firstorder and third-order frequencies, respectively, and the frequency content of the measured data reflected the rationality of Equation (1) which considers 1st and 3rd order frequencies. This figure also shows that when the swaying frequency is about $1.2-1.5 \mathrm{~Hz}$ and $1.6-1.8 \mathrm{~Hz}$, their corresponding peak values are larger than other, may be due to the natural frequency of empty structure spanning the range $2.5-3.5 \mathrm{~Hz}$.

The basic evaluation methods for measuring vibration are three forms of acceleration: peak acceleration limits (was cited in NBCC [26]); acceleration root mean square (RMS) of weighted frequency; and vibration dose values (VDVs). The latter two are acceptable by most standards (BS7085 [27], BS6472 [28], and ISO10137 [29]) to quantify vibration levels. They are calculated by Equation (6), and $a(t)$ is a measured acceleration of structure.

$$
\begin{aligned}
a_{w}(t) & =W(f) \cdot a(t), \\
a_{\mathrm{wp}} & =\max \left|a_{w}(t)\right|, \\
a_{\mathrm{wrms}} & =\left[\int_{0}^{T} a_{w}^{2}(t) d t\right]^{0.5}=\left(\lim _{\lambda \rightarrow 0} \sum_{i=1}^{n} a_{w}^{2}\left(\zeta_{i}\right) \cdot \Delta t_{i}\right)^{0.5} \\
& =\left(\sum_{i=1}^{n}\left[W(f) a\left(t_{i}\right)\right]^{2} \cdot f^{\prime}\right)^{0.5}, \lambda=\max \left\{\Delta x_{1}, \Delta x_{2}, \ldots, \Delta x_{n}\right\}, \\
a_{\mathrm{VDV}} & =\left[\int_{0}^{T} a_{w}^{4}(t) d t\right]^{0.25}=\left(\lim _{\lambda \rightarrow 0} \sum_{i=1}^{n} a_{w}^{4}\left(\zeta_{i}\right) \cdot \Delta t_{i}\right)^{0.25} \\
& =\left(\sum_{i=1}^{n}\left[W(f) a\left(t_{i}\right)\right]^{4} \cdot f^{\prime}\right)^{0.25}, \lambda=\max \left\{\Delta x_{1}, \Delta x_{2}, \ldots, \Delta x_{n}\right\},
\end{aligned}
$$




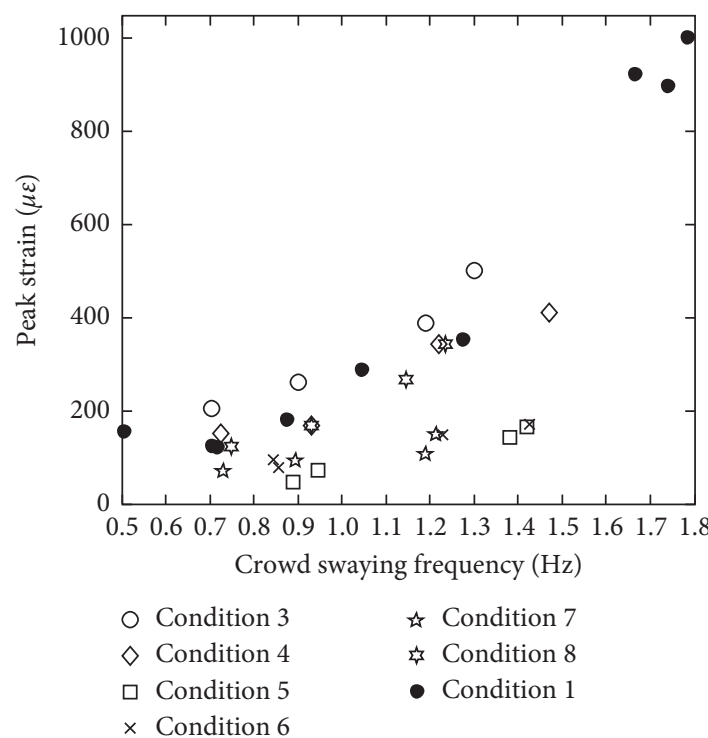

(a)

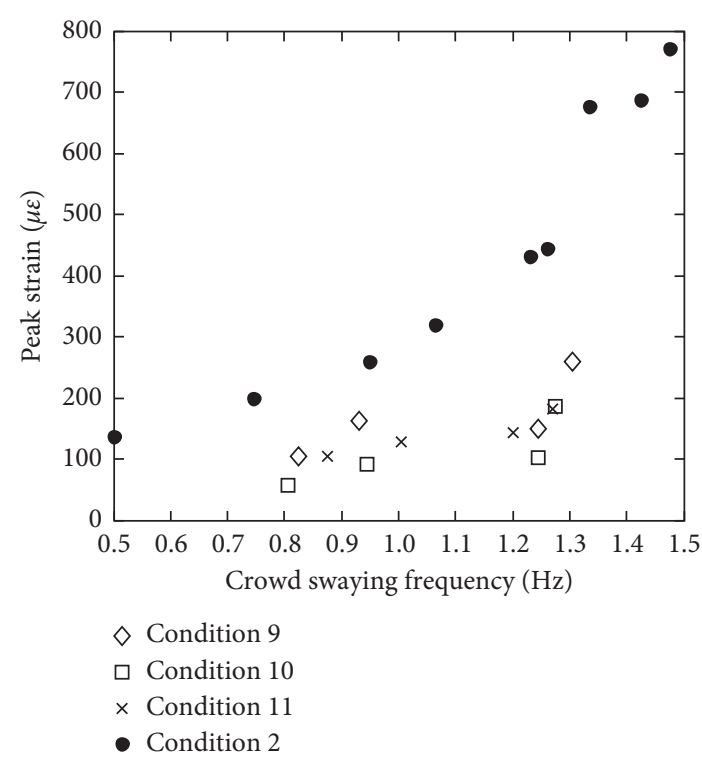

(b)

Figure 12: The maximum structural strains at different crowds swaying. (a) Standing crowd swaying and (b) seated crowd swaying.

with $a_{w}(t)=$ frequency weighted acceleration in $\mathrm{m} \cdot \mathrm{s}^{-2}$; $W(f)=$ frequency-weighting function from ISO2631-1 [30], and $f$ is the frequency; $a_{\mathrm{wp}}(t)=$ frequency weighted peak value of acceleration in $\mathrm{m} \cdot \mathrm{s}^{-2} ; a_{\mathrm{wrms}}(t)=$ frequency weighted peak value of acceleration in $\mathrm{m} \cdot \mathrm{s}^{-2} ; a_{\mathrm{wvdv}}(t)=$ frequency weighted peak value of acceleration in $\mathrm{m} \cdot \mathrm{s}^{-1.75} ; f^{\prime}=$ sample frequency in $s ; T=$ vibration duration in $s$; and $n=$ the number data.

It is found that this structure had obvious vibration when it was occupied by the active crowd with rhythmic activities, and the structural acceleration cannot be ignored. For example, Figure 16(a) shows one time history of structural acceleration which was oscillated by twenty persons when they have rhythmic movements. Then the acceleration peak. values, RMS acceleration, and VDVs of each test condition (Table 7) result are calculated, and the scatter plots the three measures plotted against crowd swaying frequencies is shown in Figure 16(b). In this figure, also the hollow dots stand for peak values, square dots stand for RMS values, and diamond dots stand for VDVs are shown. It is found that RMS values are higher than peak value and VDVs, and the max value is about $13.49 \mathrm{~m} / \mathrm{s}^{2}$, which is out of the limits were given by Nhleko [11], BS6472 [28], BRE [31], Kasperski [32], BS6841 [33], and Setaerh [34]. Meanwhile, these participants were in panic. Bearing all this in mind, the crowd not only can increase the damping of the occupied structure but also the swaying crowd can induce the structure to experience excessive vibrations, which made crowd panic even the structure is safe, so it is necessary to predict the dynamic response of the structure when it occupied the swaying crowd.

\section{Finite Element Model of Temporary Demountable Grandstand}

Using the finite element model to predict the dynamic response of temporary grandstand is a common method [15-21] when the structure is huge and difficult to test in site. And these literatures have deemed crowd just as loads, but they not did consider human's damping and stiffness which can influence the structural dynamic performance. In order to adequately predict the dynamic performances and responses of temporary grandstand, a finite element model of temporary grandstand which accommodates one thousand persons is created by ABAQUS software. The three-dimensional finite element model consists of nine kinds of members from (1) to (9) which are shown in Table 7 , and the tube standards and railings and tubular raking beams are modeled by beam elements (element type B31), tube braces and ledgers are modeled by one-node truss elements (element type T3D2), and other members are modeled by four-node shell elements (element type S4R), just like seat and stands plate. The following values of material properties and member sizes are listed in Table 9, $R$ stands for the radius of member section, $t$ stands for the thickness of member section, $H$ is the height of member section, and $B$ is the width of member section. The structure has a total length $27.9 \mathrm{~m}$, depth of $17 \mathrm{~m}$, and height of $8.6 \mathrm{~m}$ (Figure 17), the arrangement of bracing members is based on a temporary grandstand which was used for practice in Nanjing 2014 Youth Olympic Games.

There are 67080 elements in this model and the interaction between decks and supporting members is done by the tie connection. The interaction between base jacks and ground are simplified into pin rocker bearing, so only the constraint condition UR1(front to back direction) and UR3 (vertical direction) are not restricted The ideal elastoplasticity model is chosen as the constitutive model of steel material, and Poisson's ratio is 0.3 . Three analysis steps are considered: (1) general, static general, to investigate the static responses of structure when crowd forces are assumed as static forces; (2) linear perturbation, 

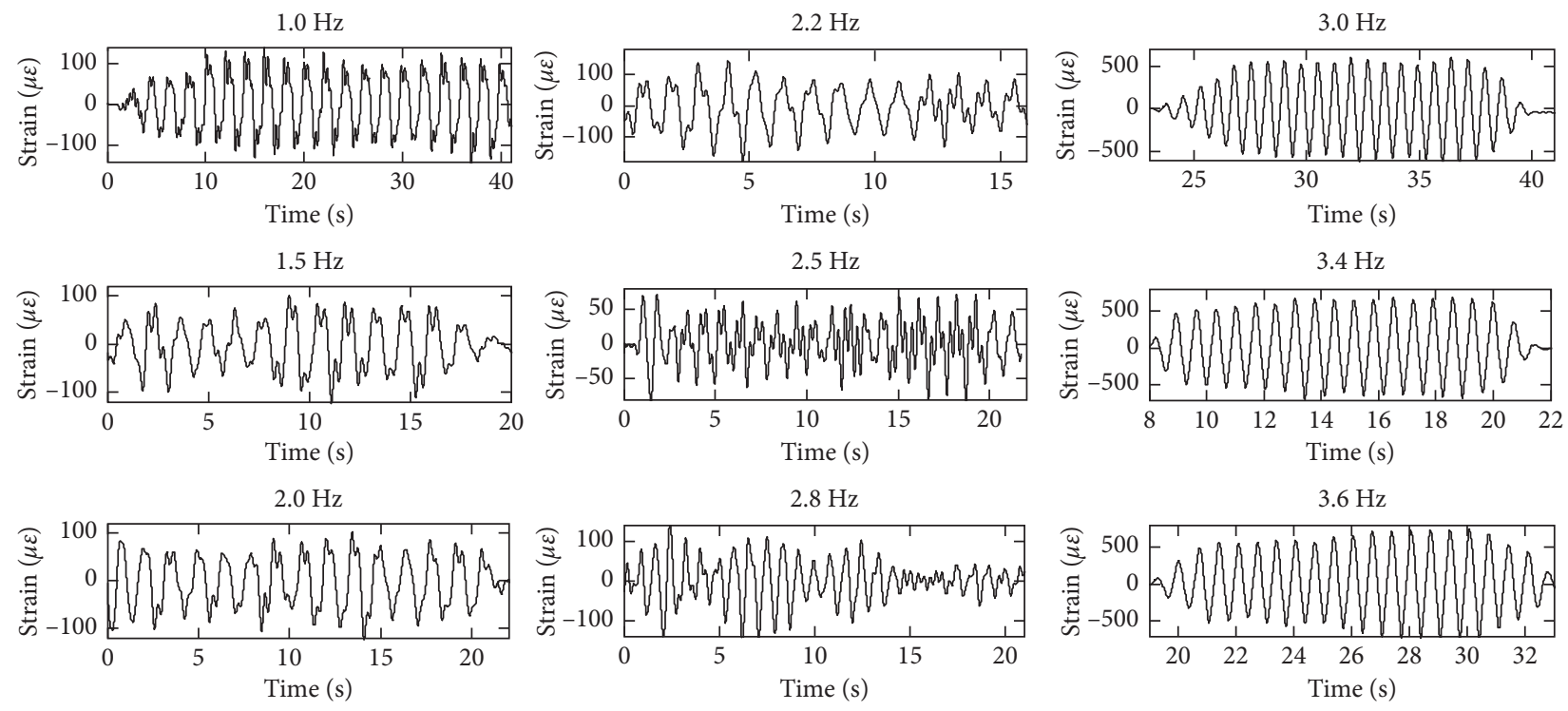

(a)
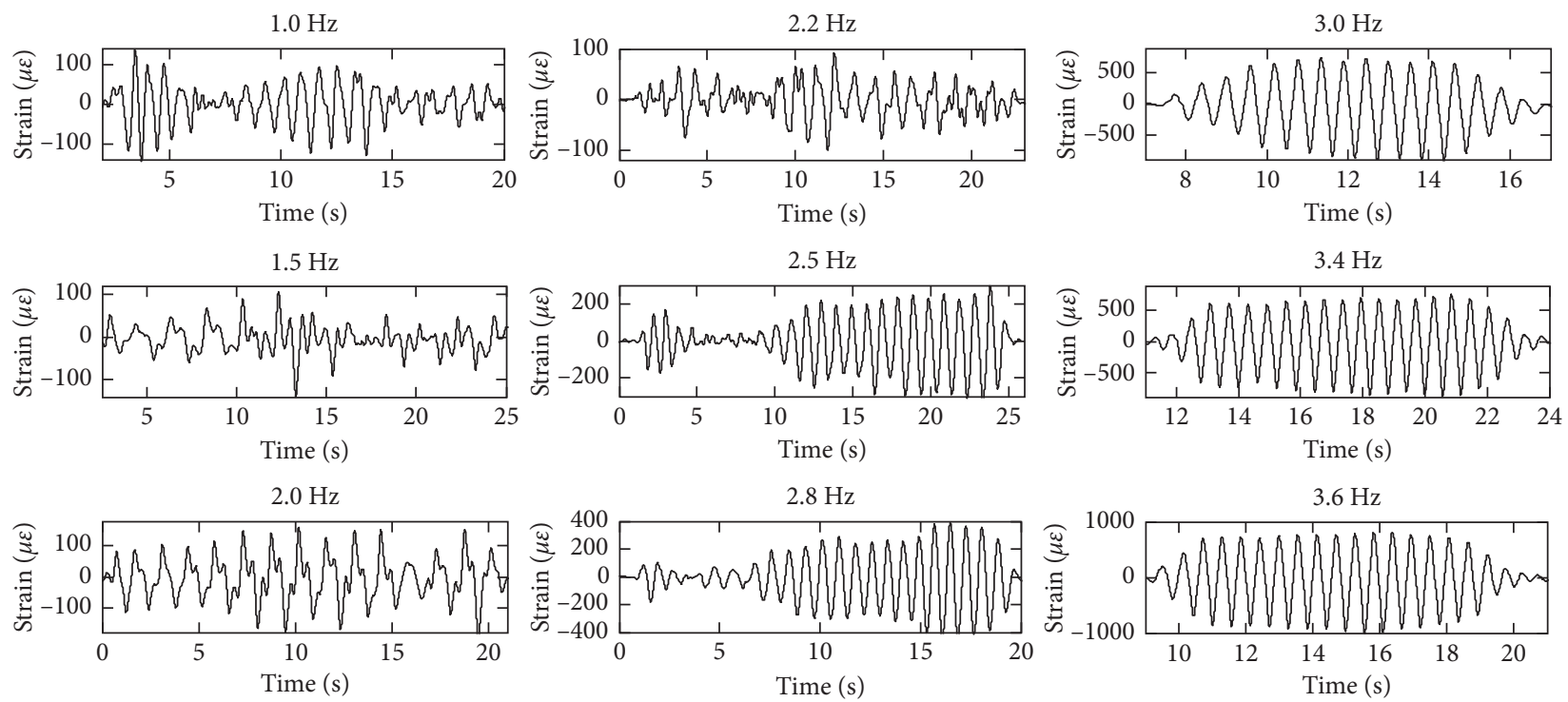

(b)

FIGURE 13: The structural strain of point S25 when all crowd swaying. (a) The results of standing crowd had swaying and (b) the results of seated crowd had swaying.

frequency, to investigate the dynamic performance of structure; (3) linear perturbation, model dynamics, to investigate the dynamic responses of structure when crowd forces are assumed as active forces.

When the crowd forces are assumed as imposed load, according to the standard BS6399-1 [35], the vertical load is $5.2 \mathrm{kN} / \mathrm{m}^{2}$, the left to right load is $0.52 \mathrm{kN} / \mathrm{m}$, and the front to back load is $1.37 \mathrm{kN} / \mathrm{m}$. After computing this model, the max Mises stress was obtained, and it is $265 \mathrm{MPa}$, which is lower than yield stress in Table 9, and the max displacement is $30 \mathrm{~mm}$ (Figure 18(b)).

4.1. Dynamic Parameters. In order to determine the natural frequencies and mode shapes of structure at $X$ direction (front to back), $Y$ direction (vertical), and $Z$ direction (left to right), respectively, the dat format of resulting file is analyzed (Figure 19). From this file, the total mass of structure is $38437 \mathrm{~kg}$, the total effective mass of the structure at $X$ direction is $36671 \mathrm{~kg}$ and at $Z$ direction is $35532 \mathrm{~kg}$, which are more than 90 percent of total mass when considered the number mode shape is 15 . The eigenvalue, frequency, generalized mass, and participation factor (effective mass) are given in Table 10. The frequency which corresponds to the participation factor (effective mass) having a big value is considered as the natural frequency, so the main mode shape is 8 th and the natural frequency is 9.24 at $X$ direction, while the main mode shape is between 1 st and 7 th, and the frequency ranges from 1.62 to $6.24 \mathrm{~Hz}$ at $Z$ direction, which are close to the result of this 


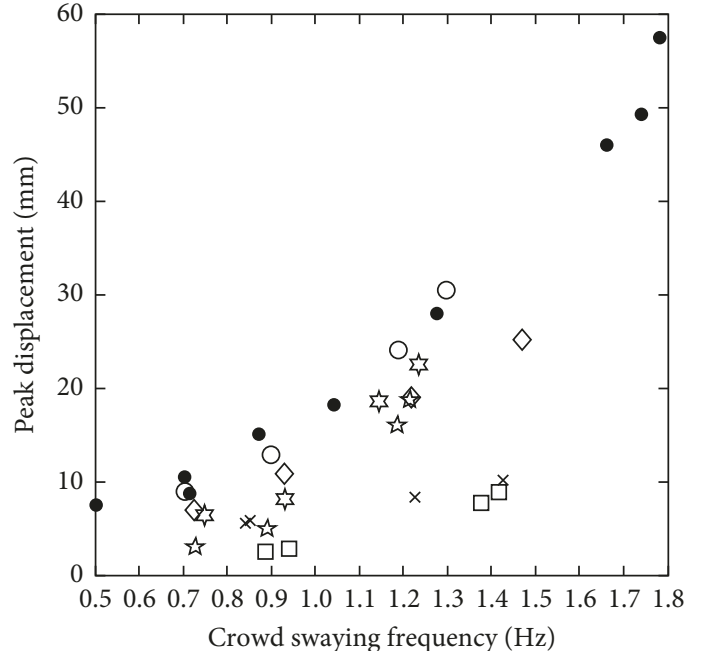

- Condition 1

Condition 3

$\diamond$ Condition 4

$\square$ Condition 5

(a)

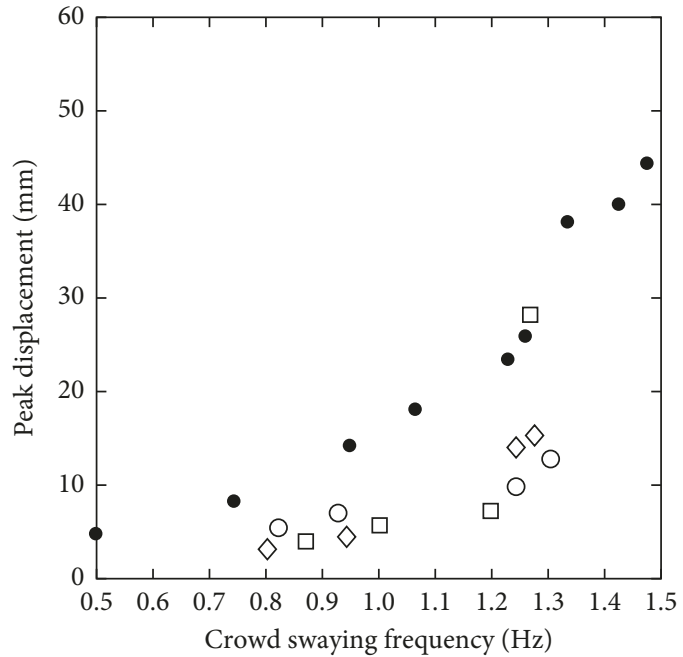

O Condition 9

$\diamond$ Condition 10

$\square$ Condition 11

- Condition 2

(b)

Figure 14: The maximum structural displacements at different crowds swaying. (a) Standing crowd. (b) Seated crowd.

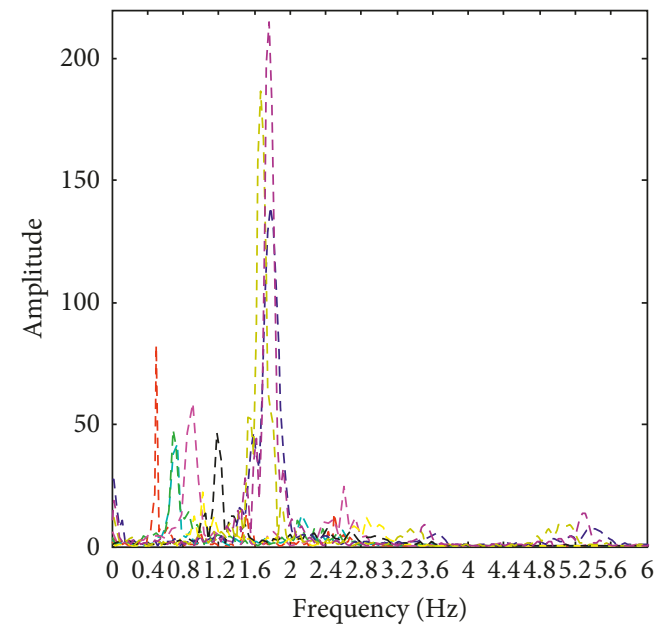

$$
\begin{array}{ll}
--f=0.505 \mathrm{~Hz} & --f=0.715 \mathrm{~Hz} \\
---f=0.705 \mathrm{~Hz} & ---f=0.875 \mathrm{~Hz} \\
--f=1.045 \mathrm{~Hz} & ---f=1.275 \mathrm{~Hz} \\
---f=1.740 \mathrm{~Hz} & ---f=1.665 \mathrm{~Hz} \\
---f=1.785 \mathrm{~Hz} &
\end{array}
$$

(a)

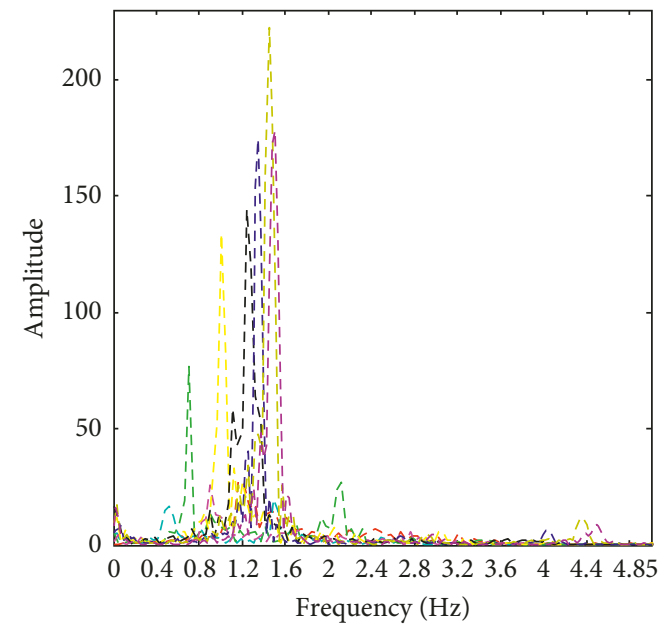

$$
\begin{array}{ll}
--f=1.26 \mathrm{~Hz} & --f=0.50 \mathrm{~Hz} \\
---f=0.745 \mathrm{~Hz} & ---f=0.95 \mathrm{~Hz} \\
--f=1.065 \mathrm{~Hz} & ---f=1.23 \mathrm{~Hz} \\
---f=1.335 \mathrm{~Hz} & ---f=1.425 \mathrm{~Hz} \\
---f=1.475 \mathrm{~Hz} &
\end{array}
$$

(b)

Figure 15: The structural response frequencies with crowds swaying. (a) Standing crowd swaying and (b) seated crowd swaying.

paper and measured results [9]. Each mode shape is shown in Figure 20, the first picture depicts the mode shape of the structure at front to back direction, which shows the bending of bottom of standards in $X$ direction. Other seven pictures show the mode shape from 1 st to 7 th at left to right direction, and there are single bending shapes in the first four modes and double bending shapes in the fifth and sixth mode, while the torsion of shape occurs in the seventh mode.
4.2. Dynamic Responses. Three load conditions are simulated: 1000 persons have $100 \%$ rhythmic swaying movement; 235 persons have $100 \%$ rhythmic swaying movement; 235 persons have stochastic swaying movement. The swaying frequencies are also considered as nine frequencies, from $1.0 \mathrm{~Hz}$ to $1.8 \mathrm{~Hz}$ at an interval of $0.1 \mathrm{~Hz}$, and the $20 \mathrm{~s}$ time history of dimensionless force curves is calculated by Equation (1) which are shown in Figure 20, and the swaying 


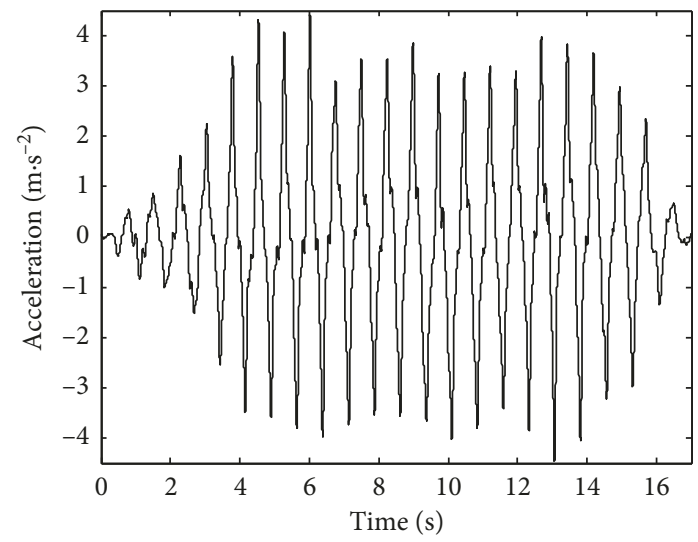

(a)

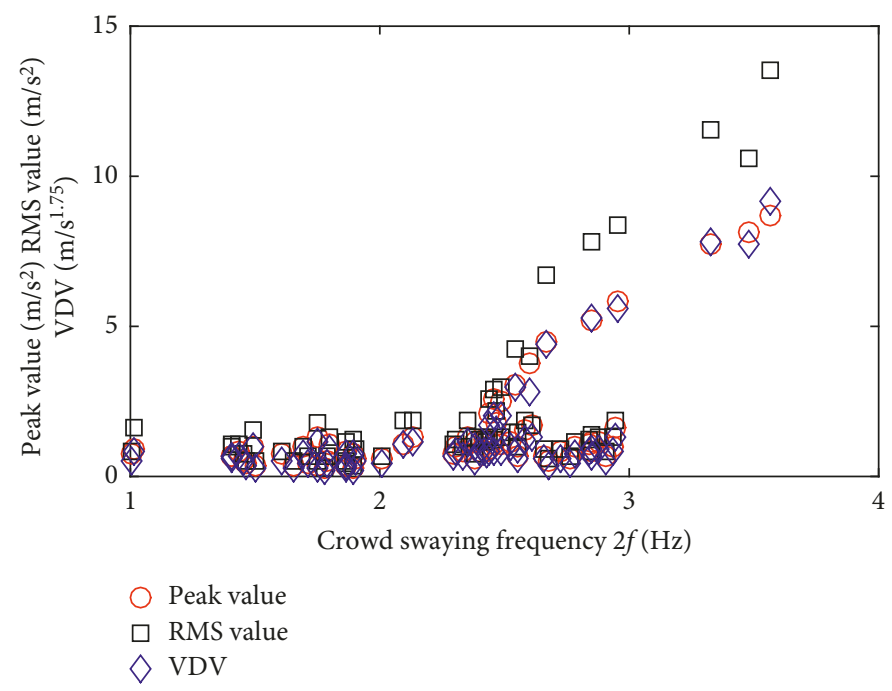

(b)

FIgURE 16: The structural acceleration peak value, RMS, and VDV relationship with crowd swaying frequencies. (a) Structural acceleration curve of seated crowd with $1.8 \mathrm{~Hz}$ swaying and (b) three measures acceleration against crowd swaying frequencies.

TABLe 9: Material properties and members size of model.

\begin{tabular}{|c|c|c|c|c|}
\hline Members & Elasticity modulus (GPa) & Yield stress $(\mathrm{MPa})$ & Density $\left(\mathrm{kg} / \mathrm{m}^{3}\right)$ & Sizes $(\mathrm{mm})$ \\
\hline Standard & 206 & 300 & & $R=25.5, t=3.5$ \\
\hline Bracing & 206 & 200 & & $R=24, t=3.0$ \\
\hline Rail & 206 & 200 & & $R=24, t=3.0$ \\
\hline Ledger & 206 & 200 & 7850 & $R=24, t=3.0$ \\
\hline Deck & 206 & 300 & & $t=1.5$ \\
\hline Seating beam & 206 & 300 & & $H * B * t=100 * 50 * 4$ \\
\hline Triangular stepped frame & 206 & 300 & & $H * B * t=60 * 40 * 2.5$ \\
\hline
\end{tabular}

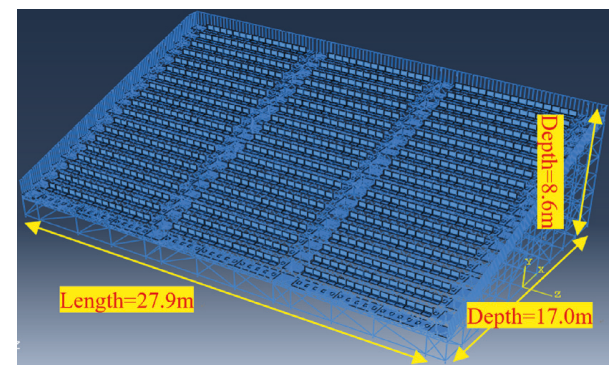

Figure 17: The finite element model of temporary grandstand.

body mass $m$ is deemed $70 \mathrm{~kg}$, the peak value of load is 140 $\mathrm{N}$. Because the area of swaying person's two feet is $0.24 \mathrm{~m} \times$ $0.18 \mathrm{~m}$, the magnitude is 23.15 in the load module when choosing "surface traction" at the model dynamic step module in ABAQUS.

(1) When 1000 persons have swaying movement, it is well known that the swaying crowd can induce forces at structure, and they can be assumed as dynamic loads in the finite element model. However, these swaying persons not only can supply the forces but also can influence the structural dynamic performances due to their body's dynamic properties. So in this model, each swaying person is assumed as single dynamic force firstly; another condition is that each swaying person is assumed as single dynamic force with stiffness and damping; in addition, the frequency of body is $2.1 \mathrm{~Hz}$, the damping ratio is 0.2 , and the model mass of body is their weight, which are referenced from Griffin [36].

When a person just only is assumed as the dynamic force, the structural dynamic responses are calculated when the forces are as those in Figure 20. It is found that the biggest instantaneous stress occurs at the bottom of standard which in the first front row (upper left picture in Figure 18), and the biggest instantaneous displacement occurs at the middle of standard in the middle rows (bottom left picture in Figure 18). The biggest instantaneous stress (displacement) plotted against each swaying frequency is shown in Figure 18 (right figure), respectively. It is clear that the biggest strain is $75.6 \mathrm{MPa}$ when swaying frequency is $1.2 \mathrm{~Hz}$, which is lower than yield stress $300 \mathrm{MPa}$, and the biggest displacement is $22.2 \mathrm{~mm}$ when swaying frequency is $1.6 \mathrm{~Hz}$.

In order to evaluate the vibration serviceability, considering persons feel the vibration which is directly from the deck, so the acceleration of same position of deck at each row is obtained and calculated its VDVs through Equation (6), and then each row plotted against structural acceleration 


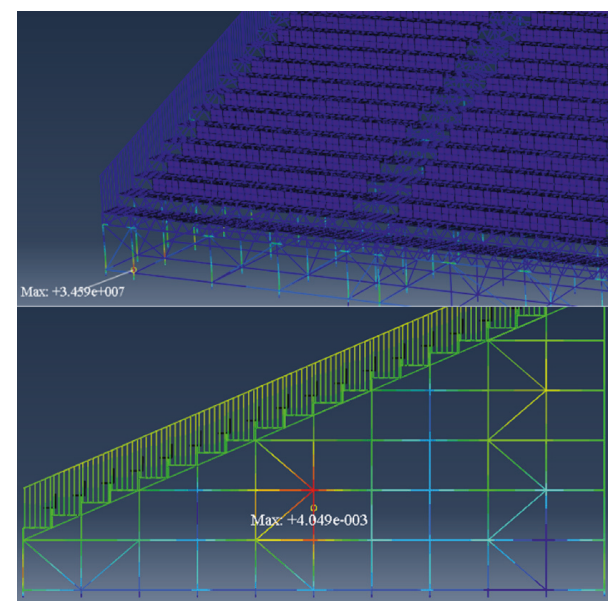

(a)
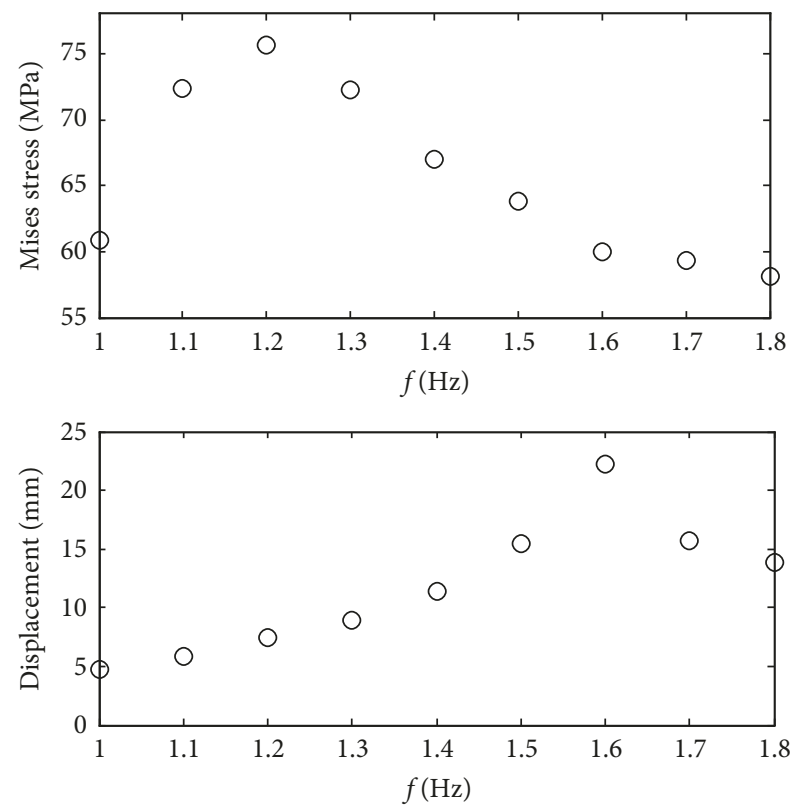

(b)

Figure 18: The significant response zone of structure and max structural response against swaying frequency.

VDVs are given in Figure 21. The scattered data show that the VDVs are increased with the number of rows, which obviously increases when swaying frequency is $1.2 \mathrm{~Hz}$ and meanwhile indicates the vibration levels of back rows is higher than front rows. The max VDV is $1.33 \mathrm{~m} / \mathrm{s}^{1.75}$ which is lower than the limit $2.4 \mathrm{~m} / \mathrm{s}^{1.75}$ that is given by Nhleko [11] and BRE [31].

(2) When a person is considered as single degree of freedom system, the model was also calculated and one of swaying frequencies results for structural acceleration nephogram as shown in Figure 22(a). The biggest instantaneous stress and displacement plotted against swaying frequency are also given in Figure 22(b), and the scattered data reveal it is significantly different from the Figure 20, and the responses are increase with swaying frequency. It is easy to see that the instantaneous stresses are higher than yield stress when swaying frequency is over than $1.5 \mathrm{~Hz}$ and the max displacement is $115 \mathrm{~mm}$, which are higher than the value in Figure 20. Besides, the VDVs of each row plotted against the number of rows are shown in Figure 22(c), and it is found that the VDVs have a slight increase with the number of rows but has an obviously increase with swaying frequency. The max value is $3.1 \mathrm{~m} / \mathrm{s} 1.75$ when swaying frequency is $1.8 \mathrm{~Hz}$, which is higher than the limit. So, it is concluded that the structure is unsafe when a swaying human was considered as single degree of freedom with dynamic forces, whereas the structure is safe and meets vibration serviceability when swaying human was considered as dynamic forces.
(3) It is an extreme case when all the persons swaying together; in fact, only a part of crowds have swaying movements in most cases, in particular, for rooters at sports or live concerts. So, the condition is that the 235 persons in the 8th row to 12 th will sway and others are passive crowd and the frequency of passive human is $2.0 \mathrm{~Hz}$ and damping ratio is 0.3 which accords to the literature [37]. This model was calculated just only when the swaying frequency is $1.8 \mathrm{~Hz}$. Firstly, the 235 persons swaying at the same direction were simulated and the structural dynamic responses are analyzed, and the results show that the max instantaneous stress is $143 \mathrm{MPa}$, which is lower than yield stress, and the max instantaneous displacement is $28 \mathrm{~mm}$ which is lower than the value $115 \mathrm{~mm}$ in Figure 22(b). Secondly, the crowd of 8th, 10 th, and 12th swaying at the same direction and the crowd of 9th and 11th swaying at opposite direction were simulated. Then the VDVs plotted against the number of rows for these two conditions are shown in Figure 23, respectively. It is found that the VDVs increase first then decrease and have a max value at the 11th and/or 12th row, and what is more, the VDVs of 235 persons who not have swayed at the same direction are lower than the results of all active crowd swayed at the same direction. The max VDV is $1.54 \mathrm{~m} / \mathrm{s} 1.75$, which is lower than the limit value $2.4 \mathrm{~m} / \mathrm{s} 1.75$.

(4) The swaying movements of the 235 persons are considered as a stochastic process, the swaying forces of active persons are different from each other. So, there are 235 different dynamic forces which are 


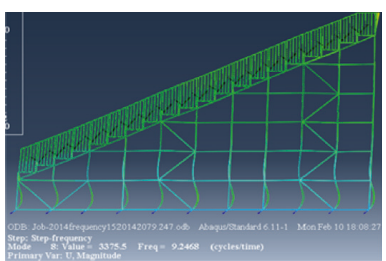

(a)

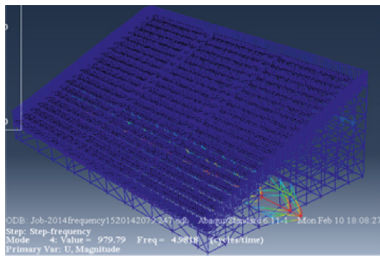

(e)

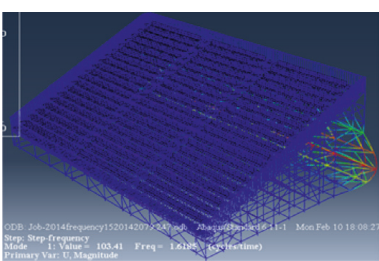

(b)

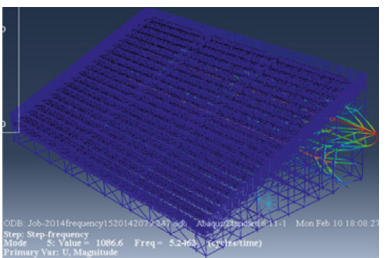

(f)

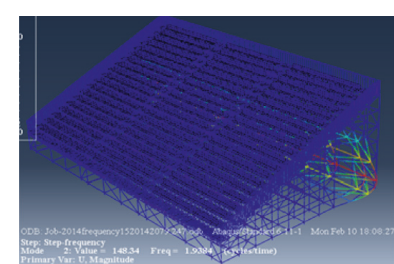

(c)

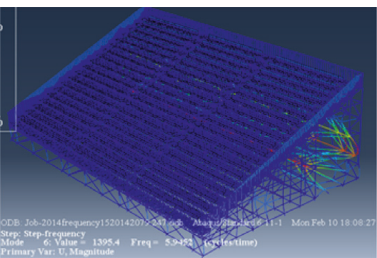

(g)

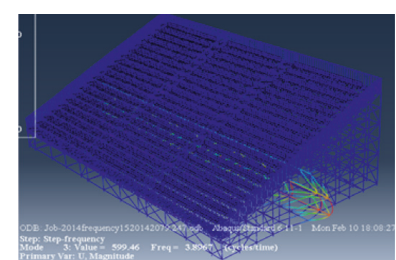

(d)

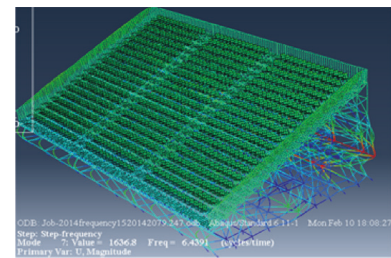

(h)

Figure 19: The structural model shape of horizontal directions. (a) $X$ direction, (b) 1 st at $Z$ direction, (c) 2 nd at $Z$ direction, (d) 3 rd at $Z$ direction, (e) 4 th at $Z$ direction, (f) 5th at $Z$ direction, (j) 6th at $Z$ direction, and (h) 7 th at $Z$ direction.
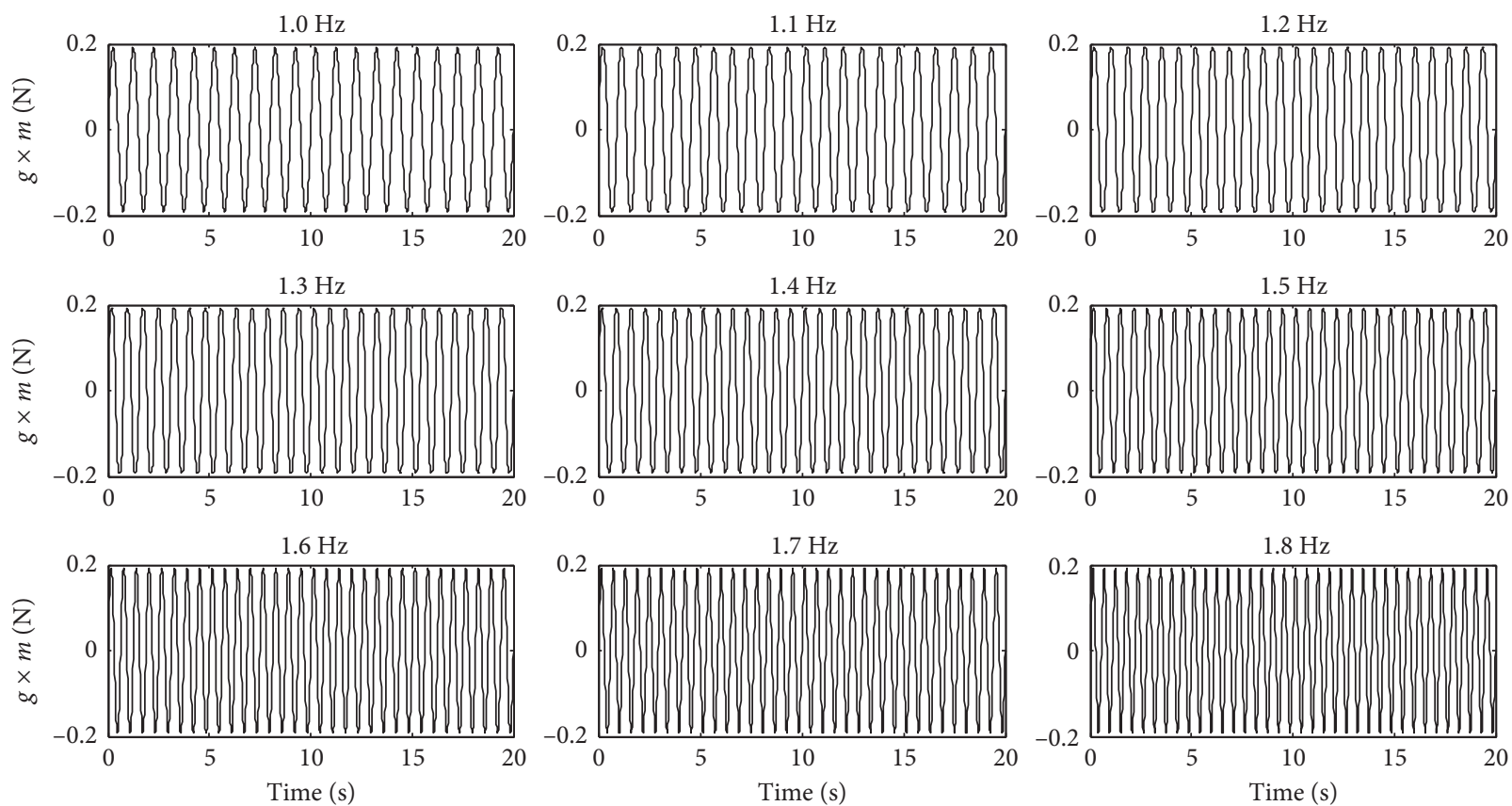

FIGURE 20: The nine simulated crowd swaying loads at nine frequencies.

TABLE 10: Calculation of eigenvalues for natural frequencies.

\begin{tabular}{lccccc}
\hline Modes & Eigenvalue & Frequency $(\mathrm{Hz})$ & Generalized mass $(\mathrm{kg})$ & Effective factor $\times 10^{-5} X$ & Effective mass $\left(\mathrm{kg} \times 10^{-5}\right) Z$ \\
\hline 1 & 103.4 & 1.62 & 834.2 & $-37.0(12)$ & $135730\left(1.54 \times 10^{8}\right)$ \\
2 & 148.3 & 1.94 & 772.6 & $9.7(0.7)$ & $137700\left(1.47 \times 10^{8}\right)$ \\
3 & 599.5 & 2.90 & 539.9 & $214(247)$ & $183280\left(1.81 \times 10^{8}\right)$ \\
4 & 979.8 & 4.98 & 521.4 & $20(2.2)$ & $247290\left(3.19 \times 10^{8}\right)$ \\
5 & 1086.6 & 5.25 & 830.7 & $78(51)$ & $97217\left(7.85 \times 10^{7}\right)$ \\
6 & 1395.4 & 5.95 & 1047.6 & $148(229)$ & $200950\left(4.23 \times 10^{8}\right)$ \\
7 & 1636.8 & 6.44 & 4839.4 & $-148(1062)$ & $-213280\left(2.2 \times 10^{9}\right)$ \\
8 & 3375.5 & 9.25 & 7903.0 & $2.1 \times 10^{5}\left(3.7 \times 10^{9}\right)$ & $-59(272)$ \\
9 & 3531.1 & 9.46 & 5049.3 & $3587(649790)$ & $-17128\left(1.48 \times 10^{7}\right)$ \\
10 & 4886.8 & 11.13 & 636.3 & $94(56)$ & $14608\left(1.35 \times 10^{6}\right)$ \\
11 & 4990.9 & 11.24 & 332.3 & $475(750)$ & $9055\left(2.73 \times 10^{5}\right)$ \\
12 & 6564.9 & 12.90 & 459.0 & $113(59)$ & $2353(4704)$ \\
13 & 7450.5 & 13.74 & 84.9 & $1651(3602)$ & $-57898\left(2.85 \times 10^{5}\right)$ \\
14 & 7518.7 & 13.80 & 132.1 & $17989(12416)$ & $-12221\left(1.97 \times 10^{5}\right)$ \\
15 & 8226.4 & 14.44 & 3.8 & & $-1803(125)$ \\
\hline
\end{tabular}




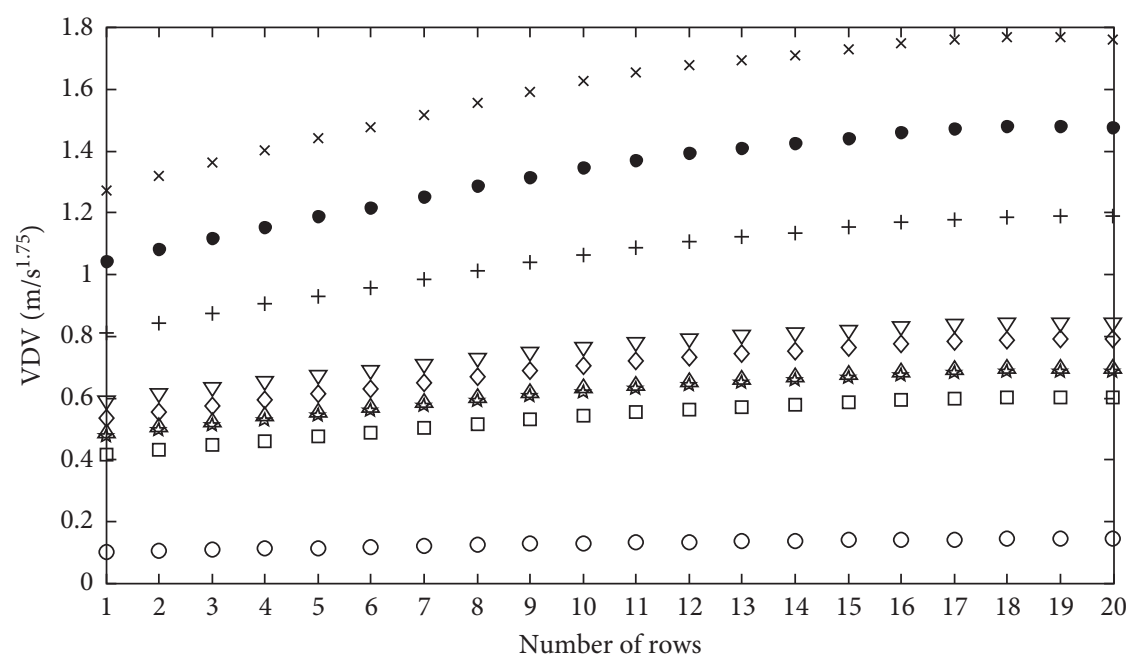
○ $f=1.0 \mathrm{~Hz}$
$\diamond f=1.5 \mathrm{~Hz}$
$\Delta f=1.1 \mathrm{~Hz}$
口 $f=1.6 \mathrm{~Hz}$
$\times f=1.2 \mathrm{~Hz}$
\f $f=1.7 \mathrm{~Hz}$
- $f=1.3 \mathrm{~Hz}$
$\nabla f=1.8 \mathrm{~Hz}$
$+f=1.4 \mathrm{~Hz}$

Figure 21: The VDVs of each row of structure.

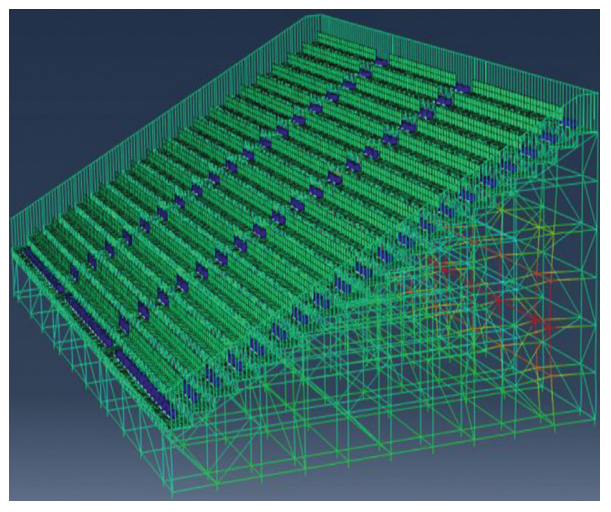

(a)
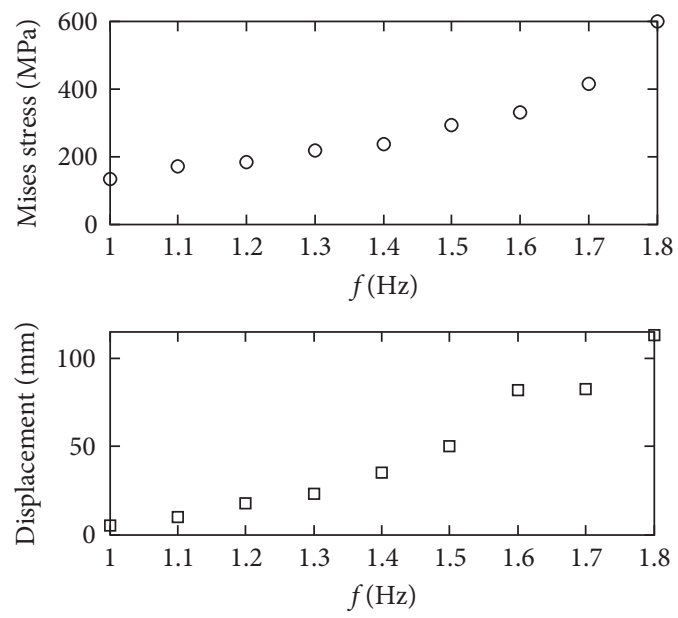

(b)

Figure 22: Continued. 


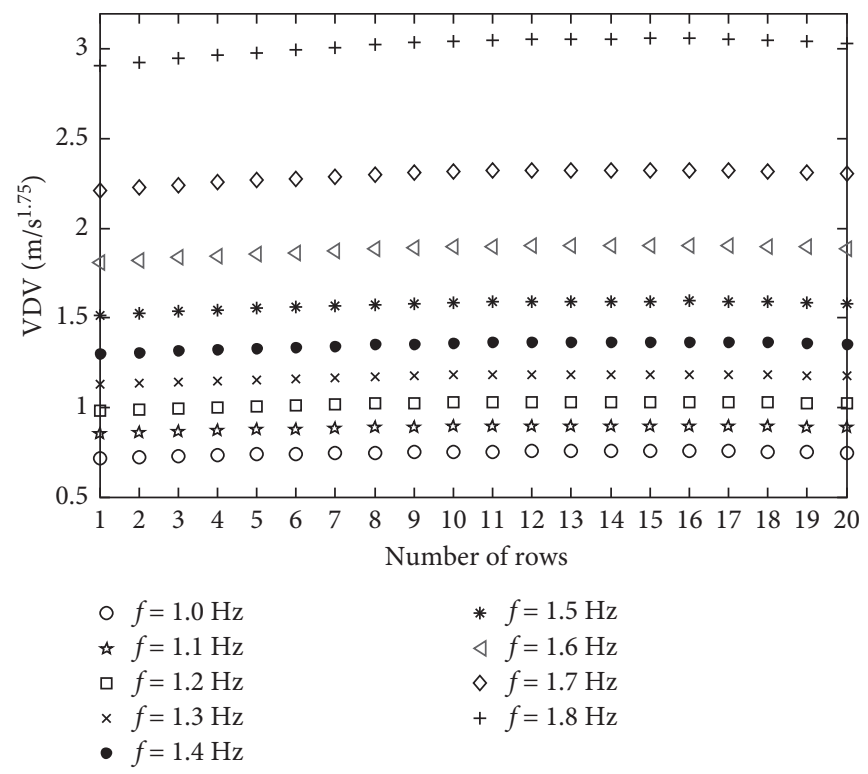

(c)

FIGURE 22: The structural responses when human assumed as mass-stiffness-damping system. (a) Structural nephogram, (b) mises stress and displacement, and (c) the VDVs plotted against the number of rows.

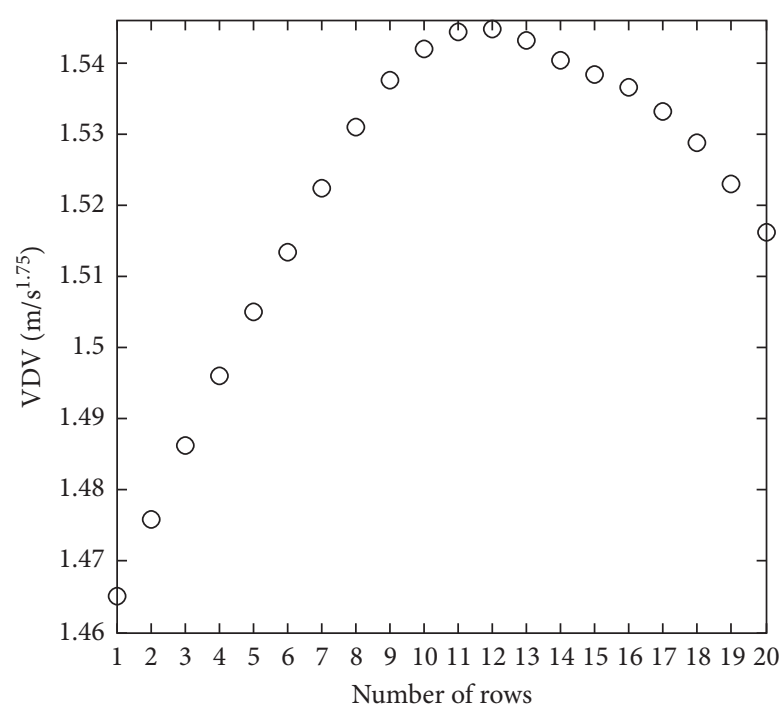

(a)

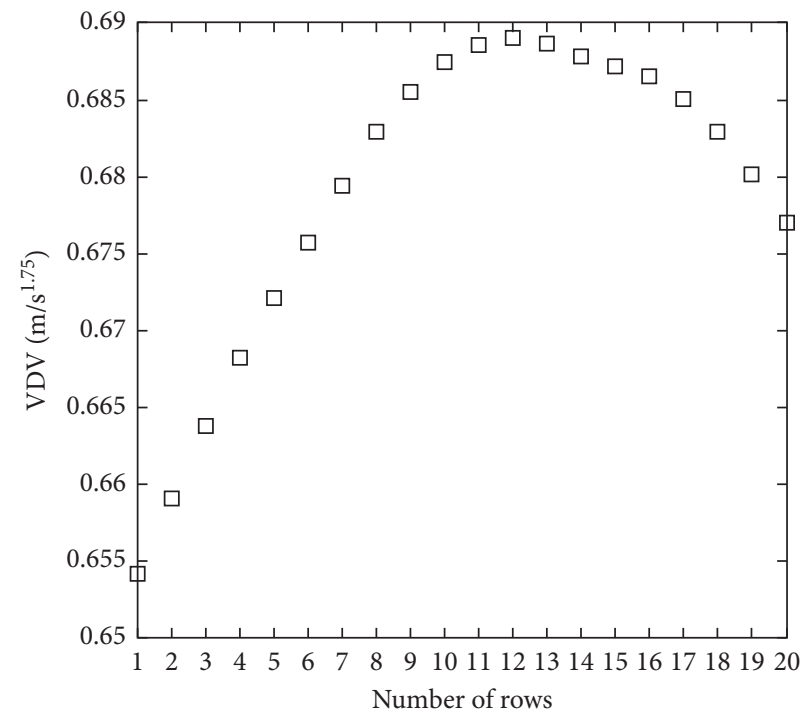

(b)

Figure 23: The VDVs of structural seating when 235 persons swaying with $100 \%$ synchronism. (a) 235 persons swaying at the same direction. (b) 235 persons swaying at not a same direction.

represented by Equation (1) as the loads of this model, and the structural dynamic responses showed that the max instantaneous stress is $70 \mathrm{MPa}$ and the max instantaneous displacement is $13.6 \mathrm{~mm}$, which are lower than the results of crowd rhythmic swaying. Also, the VDVs plotted against the number of rows are shown in Figure 24, it is clear that the VDVs increase first then decrease and have a max value of $0.72 \mathrm{~m} / \mathrm{s} 1.75$ at the 11th and/or 12th row, which is lower than the value of left picture of Figure 24, but it is higher than the value of right picture of Figure 24 . All the above results indicate that the synchronization and the direction of sway can obviously change the dynamic responses of structure.

(5) When the crowd was considered as a DOF system, the frequency of occupied structure will be changed, so the file .dat was also analyzed, and the results showed that there are only first three main mode shapes, and the corresponding frequencies are given in Table 11. It 


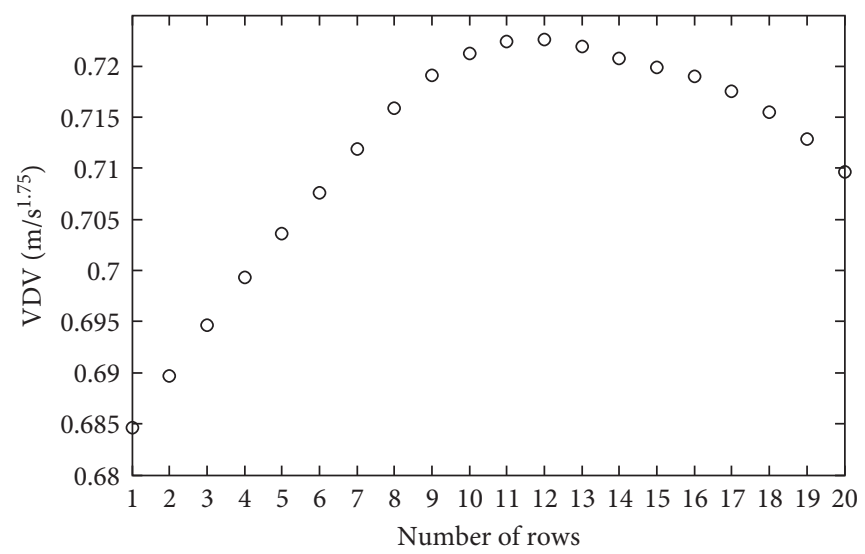

Figure 24: The VDVs of structural seating when 235 persons swaying.

TABLE 11: Structural lateral natural frequency.

\begin{tabular}{lccr}
\hline Order & $\begin{array}{c}\text { Only loads } \\
(\mathrm{Hz})\end{array}$ & $\begin{array}{c}1000 \text { swaying } \\
\text { persons as loads } \\
\text { and SDOF (Hz) }\end{array}$ & $\begin{array}{c}235 \text { swaying } \\
\text { persons as loads } \\
\text { and SDOF (Hz) }\end{array}$ \\
\hline 1 & 1.62 & 1.62 & 1.62 \\
2 & 1.94 & 1.85 & 1.79 \\
3 & 2.90 & 1.94 & 1.88 \\
\hline
\end{tabular}

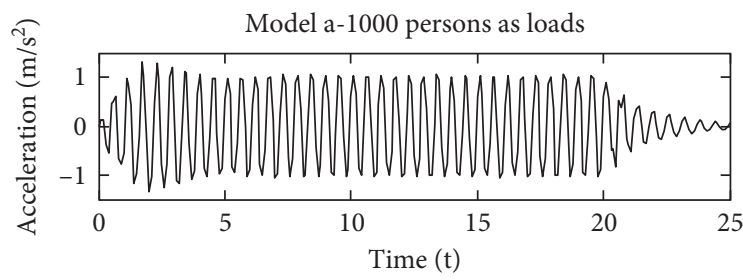

- a

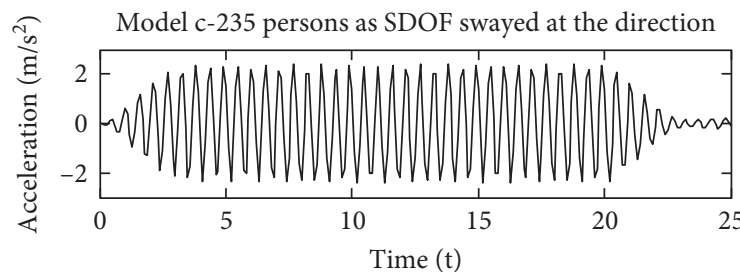

- a
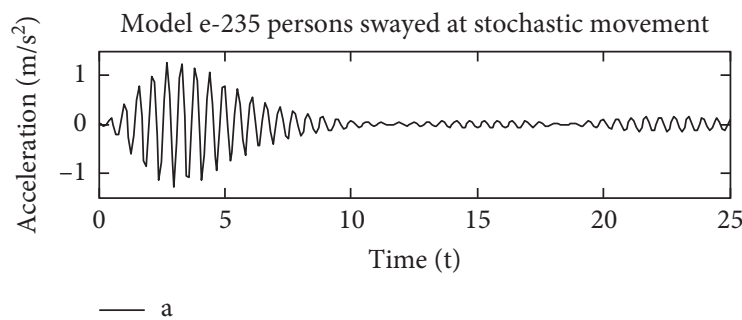

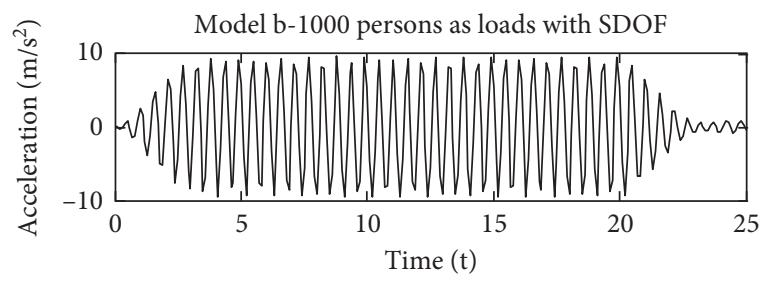

- a
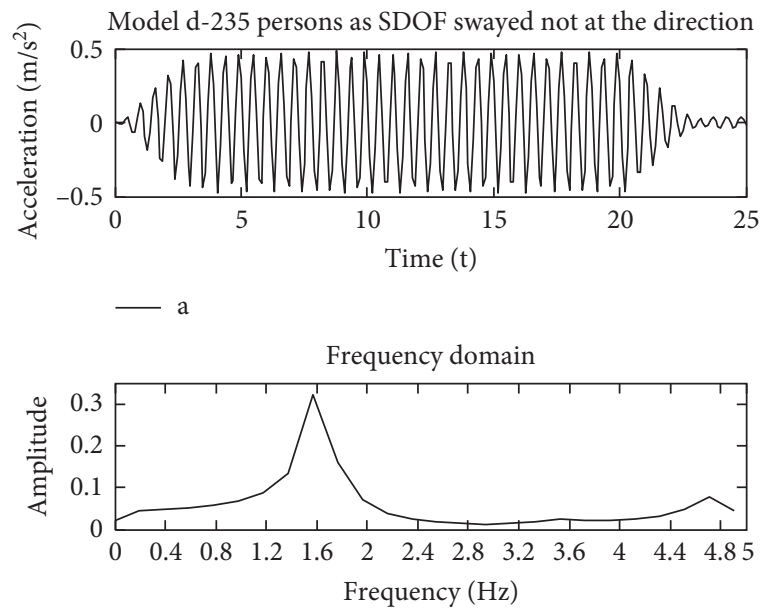

FIgUre 25: Continued. 

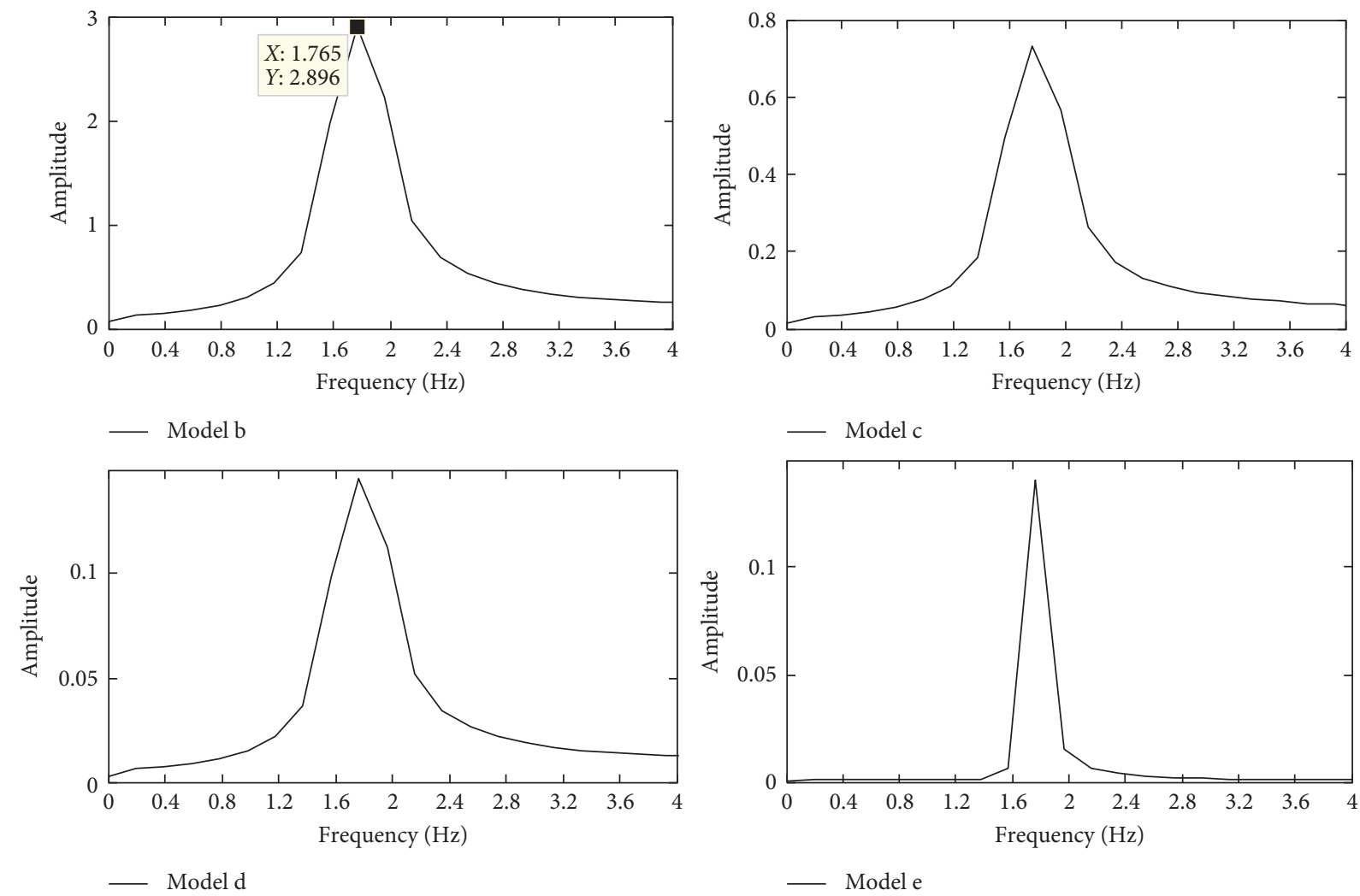

(b)

Figure 25: The time and frequency domain when human as loads and mass-stiffness-damping system. (a) The time history of acceleration and frequency domain when human as loads and (b) the frequency domain when human as mass-damping-stiffness system.

is found that just only the second- and third-order frequencies are decreased, respectively, for the frequency of empty structure and the values of model where crowds are not only active but also passive human are lower than the values of model where crowds are only active human. Then, the acceleration curves of standard of above these models when swaying frequency is $1.8 \mathrm{~Hz}$ are obtained and shown in Figure 25(a), it can be see that the peak values of these curves are different and the max value occurs in the model $b$, and the frequency domain of results are shown in Figure 25(b), which indicated that there is only one main frequency $1.74 \mathrm{~Hz}$ which is close to the excited frequency $1.8 \mathrm{~Hz}$.

\section{Conclusion}

The measurement and characterization of human-induced swaying forces in a force plate and temporary grandstand have been described in this paper. The constraint parameters of swaying forces model which derives from a semiempirical analytical model are developed for single and crowd swaying forces. The lateral natural of this test temporary grandstand ranges from $2.5 \mathrm{~Hz}$ to $3.5 \mathrm{~Hz}$ and the damping ratio is $7.3 \%$ which is higher than the general value $5 \%$; the structural dynamic responses are investigated and excessive vibration can be induced by the swaying crowd. Based on these results, a finite element model of large temporary grandstand which occupied one thousand persons was simulated; the results show that the structural lateral dynamic responses are higher when person was considered as load with stiffness and damping than person just only as load.

\section{Data Availability}

The data used to support the findings of this study are available from the corresponding author upon request.

\section{Conflicts of Interest}

The authors declare that they have no conflicts of interest.

\section{Acknowledgments}

The authors gratefully acknowledge the financial support provided by the National Science and Technology Support Project (NTSF) grant reference 2014BAK14B05 (Building and Applying the Large Safety Temporary Performance Platform). 


\section{References}

[1] F. L. Greimann and F. W. Klaiber, "Dynamic forces induced by spectators, American Society of Civil Engineers," Journal of the Structural Division, vol. 104, no. 2, pp. 348-351, 1978.

[2] C. Y. Tuan and W. E. Saul, "Loads due to spectator movements," Journal of Structural Engineering, vol. 111, no. 2, pp. 418-438, 1985.

[3] G. Pernica, "Dynamic live loads at a rock concert," Canadian Journal of Civil Engineering, vol. 10, no. 2, pp. 185-191, 1983.

[4] BBC News, "Religion show stand fall probed, Monday," 2004, http://news.bbc.co.uk.

[5] A. Bolton, "Fatal mix caused stand fall," in New Civil Engineer, pp. 5-6, Thomas Telford Ltd., Landon, 1992.

[6] V. L. Brito and R. L. Pimental, "Cases of collapse of demountable grandstands," Journal of Performance of Constructed Facilities, vol. 23, no. 3, pp. 151-159, 2009.

[7] W. E. Saul and C. Y. Tuan, "Review of live loads due to human movements," Journal of Structural Engineering, vol. 112, no. 5, pp. 995-1004, 1986.

[8] W. M. Reid, J. F. Dickie, and J. Wright, "Stadium structures: are they excited?," The Structural Engineer, vol. 75, no. 22, pp. 383-388, 1997.

[9] B. R. Ellis, T. Ji, and J. D. Littler, "The response of grandstands to dynamic crowd loads," ICE Proceedings, Structures and Buildings, vol. 140, no. 4, pp. 355-365, 2000.

[10] S. Yao, J. R. Wright, C. H. Yu, A. Pavic, and P. Reynolds, "Human-induced swaying forces on flexible structures," Structures Buildings, vol. 158, no. 2, pp. 109-117, 2005.

[11] S. Nhleko, Human Induced Lateral Excitation of Public Assembly Structures, University of Oxford, Oxford, UK, 2011.

[12] S. Nhleko, M. S. Williams, A. Blakeborough, and J. Stebbins, "Horizontal dynamic forces generated by swaying and jumping," Journal of Sound and Vibration, vol. 332, no. 11, pp. 2856-2871, 2013.

[13] S. Gibbs, Dynamic Response of Loosely Jointed Temporary Grandstand Seating, University of Manchester, Manchester, UK, 1990.

[14] C. David and Y. G. Gilbert, "Monitoring and analysis of a temporary grandstand," Structural Engineering Report No. 275, Department of Civil \& Environment Engineering, University of Alberta, Edmonton, Alberta, Canada, 2008.

[15] V. L. Brito and R. L. Pimentel, "Finite element models for vibration analysis of temporary grandstands," in Proceedings of the 8th International Conference on Structural Dynamics, Leuven, Belgium, July 2011.

[16] T. Jesus Carvalho Oliveira, V. L. Brito, and R. L. Pimentel, "Influence of seated spectators on the transverse modal properties of temporary grandstands," in Proceedings of the 9th International Conference on Structural Dynamics, Porto, Portugal, June-July 2014.

[17] L. He, C. Liu, and Z. Y. Wu, "Parametric modeling and stability analysis of temporary grandstand," Applied Mechanics and Materials, vol. 578-579, pp. 907-916, 2014.

[18] N. Lasowicz and R. Jankowski, "Numerical analysis of a temporary steel grandstand," in Proceedings of the Shell Structures: Theory and Applications-Proceedings of the 10th SSTA, Gdansk, Poland, October 2013.

[19] N. Lasowicz, A. Kwiecie, and R. Jankowski, "Experimental study on the effectiveness of polymer damper in damage reduction of temporary steel grandstand," in Proceedings of the 11th International Conference on Damage Assessment of Structures, Ghent, Belgium, August 2015.
[20] I. J. P. Marinho, L. E. Vaz, and R. L. Pimentel, "Optimization of temporary grandstands through finite element analysis," in Proceedings of the 17th International Congress of Mechanical Engineering, Sao Paulo, Brazil, 2006.

[21] J. Yuan, L. He, F. Fan et al., "Dynamic modeling and vibration analysis of temporary grandstand due to crowd-jumping loads," in Proceedings of the Proceedings of the 9th International Conference on Structural Dynamics, Porto, Portugal, June-July 2014.

[22] D. Ginty, J. M. Derwent, and T. Ji, “The frequency ranges of dance-type loads," Journal of Structure Engineering, vol. 79, no. 6, pp. 27-31, 2001.

[23] Institution of Structural Engineers, Safety Considerations for the Design and Erection of Demountable Grandstands, IStructE, London, UK, 1989.

[24] Institution of Structural Engineers/Department of the Environment, Interim Guidance on Temporary Grandstands, Institution of Structural Engineers, London, UK, 1994.

[25] Institution of Structural Engineers, Dynamic Performance Requirements for Permanent Grandstands Subject to Crowd Action: Recommendations for Management, Design and Assessment, IStructE, London, UK, 2008.

[26] NBCC, User's Guide National Building Code of Canada 2005, Structural Commentaries (Part 4 of Division B) Commentary $D$, National Building Code of Canada (NBCC), NRCC, Canada, 2005.

[27] BS 7085, Medical Contra-Indications to Participation in Experiments Involving Whole-Body Mechanical Vibration, British Standards Institution, London, UK, 1987.

[28] BS 6472, Guide to Evaluation of Human Exposure to Vibration in Buildings ( $1 \mathrm{~Hz}$ to $80 \mathrm{~Hz}$ ), British Standards Institution, London, UK, 1992.

[29] ISO 10137, Basis for the Design of Structures-Serviceability of Buildings Against Vibration, International Organization for Standardization (ISO), Geneva, Switzerland, 2007.

[30] ISO 2631, Mechanical Vibration and Shock-Evaluation of Human Exposure to Whole-body Vibration. Part 1: Vibration in Buildings ( $1 \mathrm{~Hz}$ to $80 \mathrm{~Hz}$ ), International Organization for Standardization (ISO), Geneva, Switzerland, 2003.

[31] BRE Digest 426, The Response of Structures to Dynamic Crowd Loads, BRE, Watford, UK, 2nd edition, 2004.

[32] M. Kasperski, "Actual problems with stand structures due to spectator induced vibrations," in Proceedings of the $3 \mathrm{rd} \mathrm{Eu-}$ ropean Conference on Structural Dynamics: EURODYN 96, Balkema, Rotterdam, Netherlands, June 1996.

[33] BS 6841, Guide to Measurement and Evaluation of Human Exposure to Whole Body Mechanical Vibration and Repeated Shock, British Standards Institution, London, UK, 1987.

[34] M. Setareh, "Evaluation and assessment of vibrations owning to human activity," Structures and Buildings, vol. 165, no. 5, pp. 219-230, 2012.

[35] BS6399-1:1996, Incorporating Amendment No 1 Loading for Buildings-Part 1: Code of Practice for Dead and Imposed Loads, British Standards Institution, London, UK, 2002.

[36] M. J. Griffin, Handbook of Human Vibration, Academic Press, London, UK, 1990.

[37] J. Yuan, H. Lin, F. Fan, and C. Liu, "The dynamic parameters of passive human at temporary demountable grandstands during exposure to lateral vibration," Journal of Civil Engineering and Management, vol. 24, no. 4, pp. 265-283, 2018. 


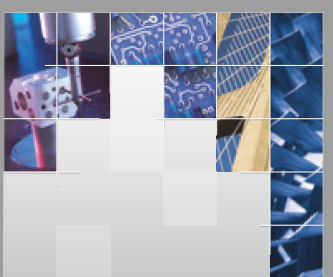

\section{Enfincering}
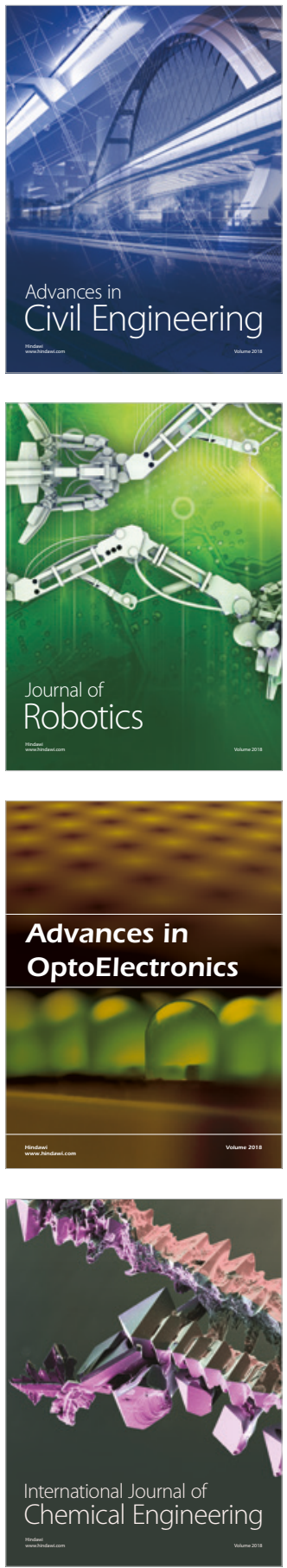

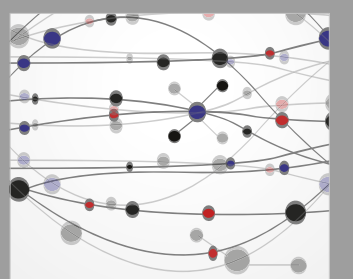

\section{Rotating \\ Machinery}

The Scientific World Journal

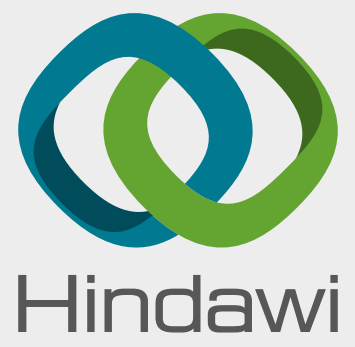

Submit your manuscripts at

www.hindawi.com
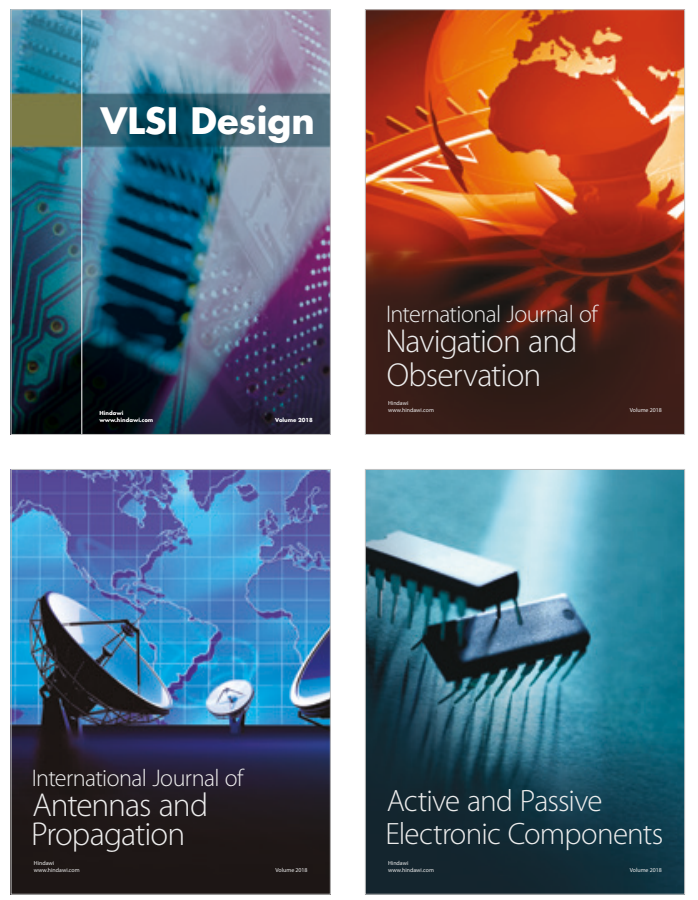
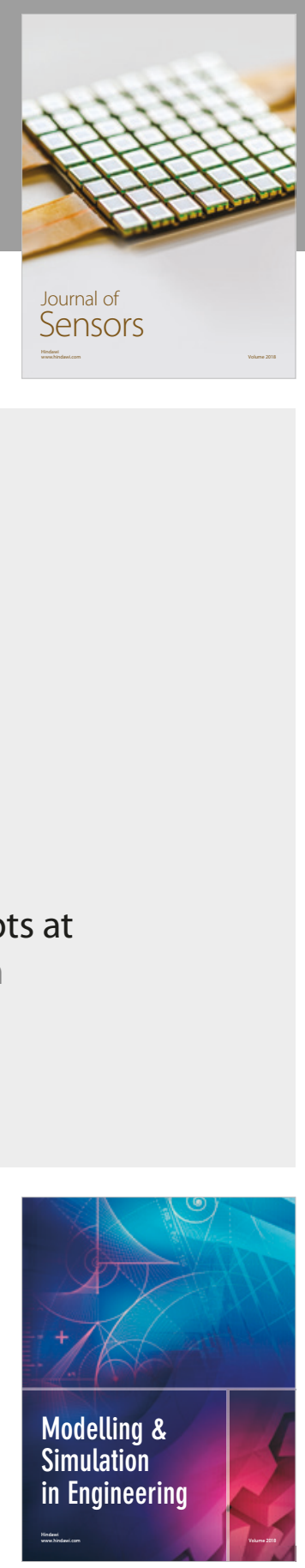

\section{Advances \\ Multimedia}
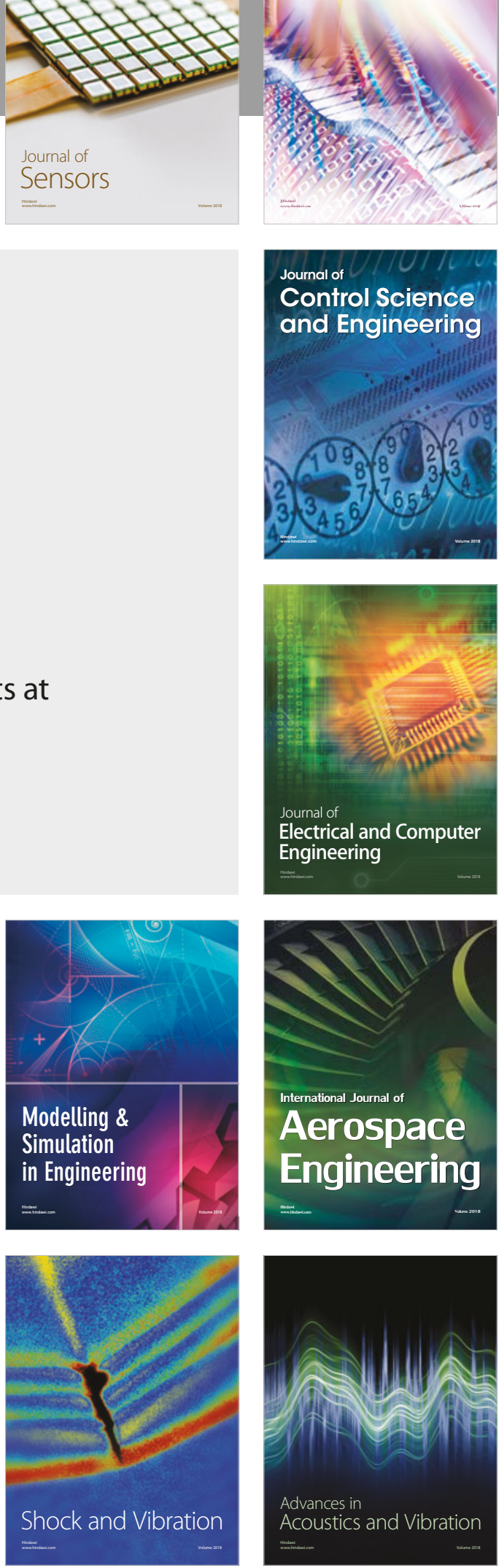